\section{S\&TR Staff}

\section{SCIENTIFIC EdITOR}

Becky Failor

Publication Editor

Dean Wheatcraft

\section{Writers}

Arnie Heller, Dale Sprouse, Sue Stull, Katie Walter

\section{Art Director \\ Ray Marazzi}

DESIGNer

Ray Marazzi

\section{Graphic ARTiST}

Treva Carey

\section{COMPOSITOR}

Louisa Cardoza

\section{Proofreader}

Catherine M. Williams

$S \& T R$ is produced by the Technical Information Department as a service for the Director's Office.

Printed in the United States of America

Available from

National Technical Information Service

U.S. Department of Commerce

5285 Port Royal Road

Springfield, Virginia 22161

UCRL-52000-96-5

Distribution Category UC-700

May 1996

This publication is a continuation of Energy \& Technology Review.

\section{Science 8 Technology}

Lawrence

Livermore

National

Laboratory
2 The Laboratory in the News

\section{Commentary on ES\&H Technology}

\section{Features}

4 Mitigating Lightning Hazards

The Laboratory is developing a guidance document for mitigation of lightning hazards to Department of Energy facilities, especially those where nuclear and high-explosive materials are handled and stored.

13 Groundwater Modeling: More Cost-Effective Cleanup by Design Innovative groundwater modeling allows us to more accurately target our groundwater cleanup efforts at the Livermore site, reducing the overall scope and cost of the project.

\section{Dual-Band Infrared Computed Tomography:}

\section{Searching for Hidden Defects}

The dual-band infrared computed tomography technologies developed at Livermore are enabling safe, rapid, quantitative nondestructive inspection and evaluation of manmade structures in three dimensions with 10 times the temperature sensitivity of single-band systems.

Research Highlight

28 Plating Shop Moves to Finish Off Waste

\section{Patents}

\section{Abstracts}
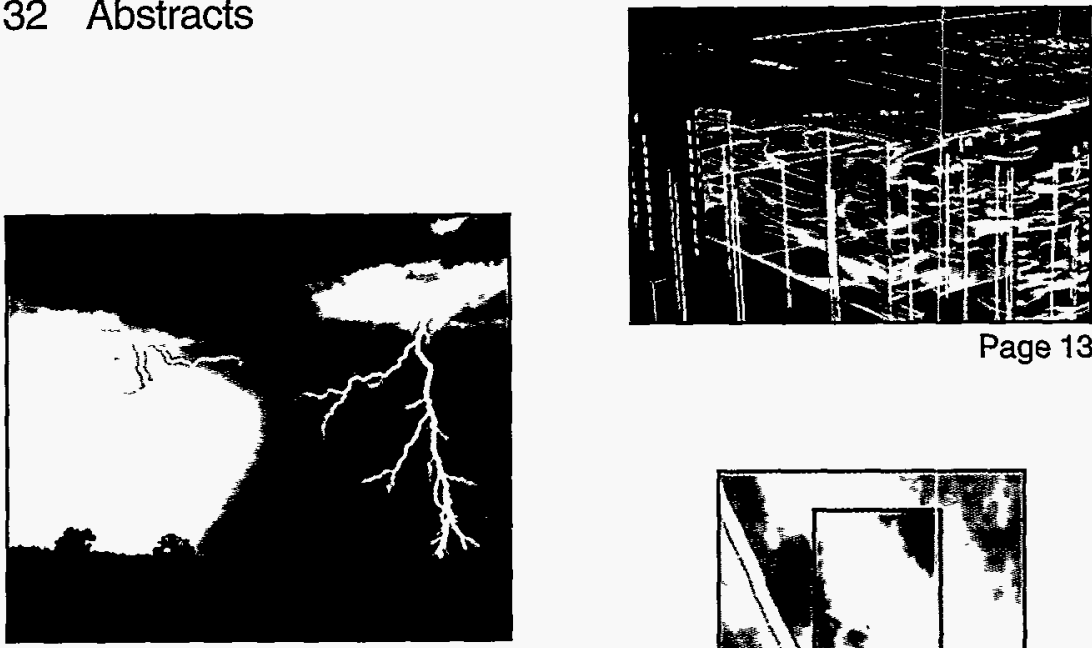

Page 13

Page 4

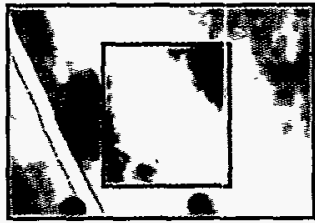

Page 23 


\section{Clementine 2 will have Lab-designed payload}

The Laboratory will provide the integrated payload for Clementine 2, an asteroid-flyby mission that will extend the legacy of Clementine 1, the spacecraft that pioneered low-cost, fast-turnaround space flight. Clementine 2 will offer the first close-up look at an Earth-crossing asteroid and also launch the first manmade objects to come in contact with an asteroid.

The mission calls for flybys of three asteroids over a year of operation, with a probe launched toward each. The probes will be autonomous micro-spacecraft that will relay data to the mother ship right up to the moment they are destroyed on impact.

Air Force Space Command will fund the program through Phillips Laboratory. The Naval Research Laboratory will build the mother ship and handle flight operations. Livermore will provide a multispectral suite of sensors (as it did for Clementine 1) as well as the probes and will analyze the mission science data. Clementine 2 will be launched in mid-1998.

Contact: Tom Karr (510) 423-3670 (tkarr@llnl.gov).

\section{AVLIS technology nears commercialization}

The Atomic Vapor Laser Isotope Separation (AVLIS) uranium enrichment process, a technology developed at the Laboratory that uses laser beams to enrich uranium for nuclear power plants, has moved a step closer to commercialization.

In March, the United States Enrichment Corporation (USEC) signed two contracts related to the commercial development of AVLIS. One, awarded to a team of contractors headed by Bechtel National Inc., is for the design of a commercial AVLIS facility. The second, awarded to Babcock \& Wilcox's Naval Nuclear Fuel Design Division, is for the preliminary design of the AVLIS separator refurbishment system and the uranium management system.

Bechtel's multiphased contract extends through the year 2003; during the first phase, the Bechtel team will employ about 50 people, mainly at USEC's operations at Lawrence Livermore. The Babcock \& Wilcox contract runs for 15 months; about 45 people will be involved in the effort, primarily at the firm's Lynchburg, Virginia, facility.

The USEC is a government corporation that produces and markets uranium enrichment services to more than 60 utilities that own and operate commercial nuclear power plants in 14 countries, including the United States.

Contact: Jim Early (510) 422-6221 (early2@llnl.gov).

\section{Astrophysicists, laser scientists eye partnership}

The exploration of uncharted areas for collaboration was the goal in late February as the Laboratory sponsored its first-ever workshop on laboratory astrophysics experiments with large lasers.

Mike Campbell, associate director for Lasers, told the gathering that he is committed to making the Lawrence Livermore's Nova laser available to the broader scientific community. He said he would like $10 \%$ of Nova shots to be collaborative basic science experiments.

With access to large lasers, astrophysicists will be able to conduct experiments in hydrodynamics, radiative hydrodynamics, magnetohydrodynamics, and radiative magnetohydrodynamics.

What started as a workshop for 40 scientists, mostly from the national laboratories, attracted 100 scientists representing 30 universities, institutes, and laboratories in eight countries. Contact: Bruce Remington (510) 423-2712 (remington2@llnl.gov).

\section{Wadsworth, Miller receive new Lab positions}

Jeff Wadsworth and George Miller, both members of Livermore's Senior Management Council, are serving in new management positions. The appointments of Wadsworth as Deputy Director for Science and Technology and Miller as Associate Director for National Security were announced earlier this year by Director Bruce Tarter.

The AD for Chemistry and Materials Science since 1994, Wadsworth now serves as the key executive responsible for the quality of science and technology in Livermore's scientific and technical programs. Among his responsibilities are collaborative research with the University of California and oversight of LLNL's Department of Defense Programs Office and its Office of Industrial Partnerships and Commercialization.

An Associate Director since 1985, Miller moves from the position of AD for Defense and Nuclear Technologies to his new job, which gives him responsibility for developing a strategic and tactical plan that appropriately defines Livermore's role in national security. Contact: LLNL Media Relations Office (510) 423-3118. 


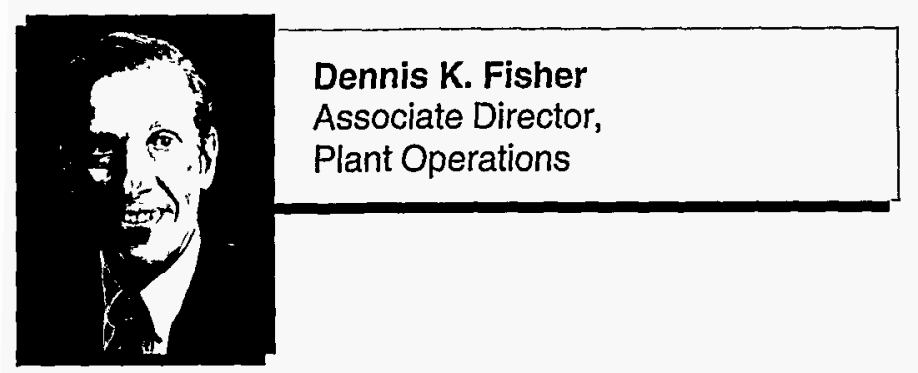

$\mathbf{T}$ ECHNOLOGIES that detect hazards and prevent exposures and injuries in the workplace have always been key tools of the Laboratory's safety and health protection programs. In addition, since the 1980s, we have been using technology to help us develop innovative solutions to complex problems such as groundwater contamination, legacy waste disposal, and pollution. Now, technology is proving to be a valuable ally in reducing the cost of environment, safety, and health (ES\&H) training and compliance activities. This issue of Science \& Technology Review presents important examples of Livermore ES\&H successes in our workplace and in a larger environmental context. They represent our continuing effort to make the $\mathrm{Lab}$-and the world at large-a safe and healthy place to work and live.

\section{Solutions for Workplace Hazards}

One major focus of our ES\&H research and development is to supply solutions to unusual workplace hazards. In one solution-protecting us from natural phenomena such as earthquakes and lightning-Livermore engineers have developed design standards for various facilities (see p. 4 of this issue). Another solution is the stainless steel high-efficiency particulateair (HEPA) filter, which is fireproof and waterproof and made especially for use in extreme environments. Because of our need to monitor hazardous environments, we have been involved in developing techniques for rapid dosimeter readouts; a realistic phantom, or dummy, for calibrating plutonium lung counters; and a miniature pump-driven air-sampling device worn by workers to monitor nearby hazardous chemicals.

Our special expertise in evaluating protective clothing and equipment has led to a sophisticated system for testing firefighting gear against exposure to direct flame and an experimental facility for evaluating respirators for their ability to protect humans under a variety of conditions. This work has led to the development of a face mask that alerts the firefighter to high carbon monoxide conditions, such as those created during wildfires, and techniques for evaluating clothing that protects against chemical agents.

Injuries resulting from repetitive motion-like carpal tunnel syndrome-are the fastest growing cause of lost time at LLNL. To assist in designing keyboards that cause less repetitive strain, we have been developing techniques to analyze the biomechanical effects of various keyboards.

\section{Cleanup, Prevention, Lower Costs}

When groundwater contamination from solvents was first discovered at LLNL in 1983, we conducted a study to characterize the complex geological structure underneath the Laboratory site. Our new techniques for monitoring our wells provide the basis for sophisticated hydrostratigraphic models of the groundwater flow and contaminant transport (see $S \& T R$, January-February 1996). These models are now being used in simulation codes (see p. 13) to optimize time-and moneyspent to use our smart "pump and treat" process for cleaning up the site. Our work in artificial neural networks and subsurface contaminant modeling will be a key to future restoration efforts.

To help prevent pollution, we have made extensive investments in plating equipment and plating techniques (see p. 28) to eliminate a major waste stream. Now our plating processes are safer for workers, use materials that are less hazardous, and create less waste. We even recycle and reuse the rinse water, which is cleaner than the water coming onto our site. We also have identified numerous substitutes for ozone-depleting solvents, many of which do a better cleaning job than the original product, and we developed a portable mass spectrometry system to quantify surface contamination levels on parts and equipment to provide real-time feedback during cleaning operations.

We are using the latest computer technologies to ensure compliance with various safety and environmental regulations and to reduce costs. For example, barcode scanners and portable computers are used to track waste containers and stored chemicals throughout our facilities; computer-based documentation allows immediate, online access to manuals and chemical hazard data sheets and permits supervisors to quickly review the certification records of their employees; and we are finding the World Wide Web to be a cost-effective and convenient way for employees to keep up-to-date in their training.

By using our specialized skills and working systematically on the Laboratory's specific ES\&H requirements, we can impact the standard of excellence in ES\&H for our Laboratory and in the larger environmental context as well. 


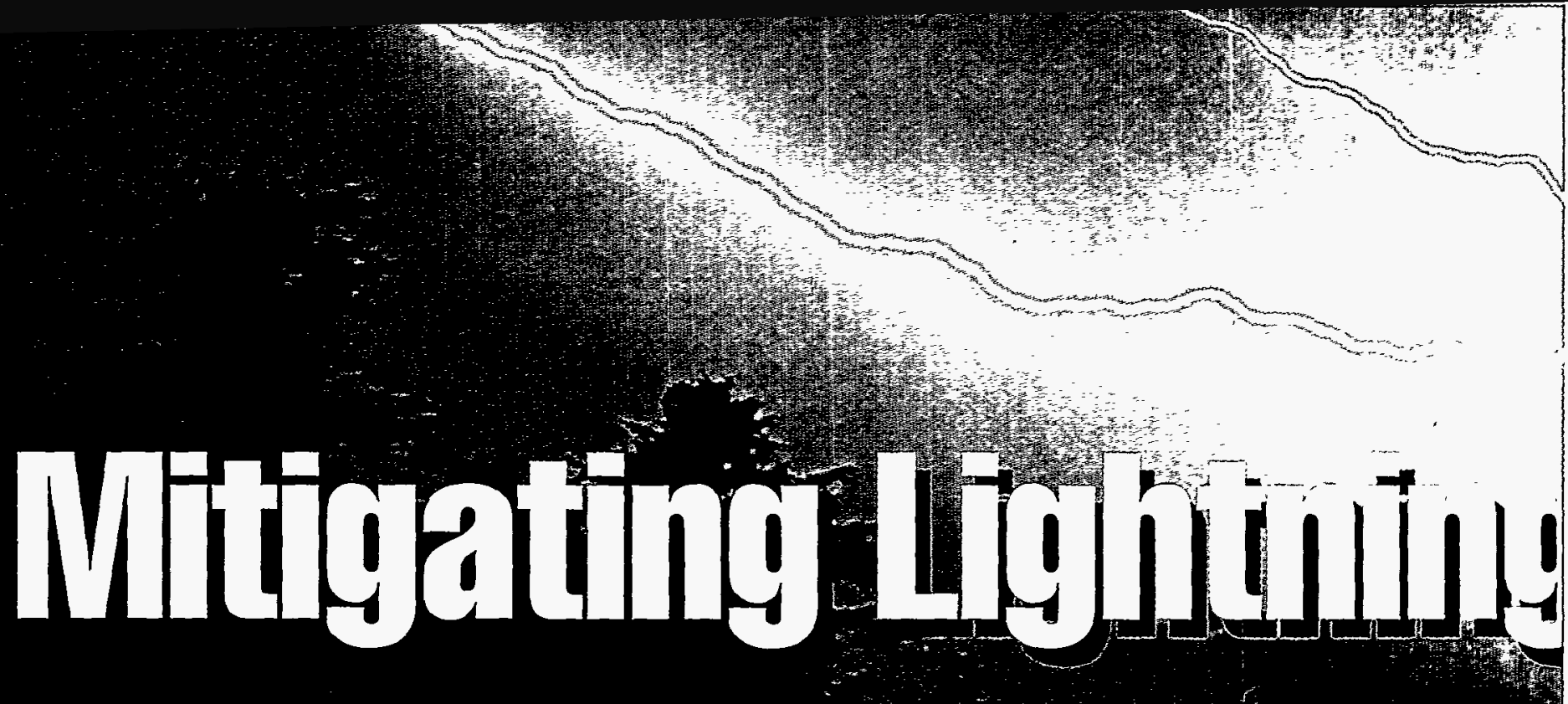

\section{Lawrence Livermore engineers' investigations of}

lightning, its hazards, and how to protect against them

have led to the development of guidance to aid in dealing with

the effects of lightning on DOE facilities, particularly those where nuclear

and high-explosive materials are handled and stored. Our guidance document

provides risk managers with a unified and graded method for attaining lightning safety.

$\mathbf{T}$

HE awesome sound and light show of a thunderstorm has always been a source of fear and wonder. At any time some 2,000 thunderstorms are in progress around the globe, causing the majority of forest fires and, in the U.S. alone, hundreds of millions of dollars in property losses. Lightning is also the leading weather-related killer in the U.S., causing from 100 to 200 deaths annually.

Despite these facts, most engineers and architects have at best only a rudimentary knowledge of lightning and protection methods, says Richard Hasbrouck, LLNL engineer in the Defense Sciences Engineering Division within Electronics Engineering. A lightning expert,
Hasbrouck is co-author of the draft "Lightning Hazard Management Guide" for the Department of Energy.

"Lightning and its associated effects are a mystery to many engineers because these subjects are not included in most engineering curricula," he says. Department of Energy managers whose job it is to assure the mitigation of natural phenomena hazards (such as lightning) for an operation or facility must contend with a hodgepodge of scientific data related to lightning, commercial products (some of questionable worth), unrealistic building codes, folklore, and halftruths. As a result, he says, many facilities, instruments, and control systems are vulnerable to damage or lightning-induced upset or malfunction.

Hasbrouck points out that earlier generations of electrical and electronic systems and components used vacuum tubes, relays, and analog control and computation devices that were intrinsically more robust against the effects of lightning than are today's solid-state, microprocessor-based systems. Brief overvoltages caused by lightning and manmade transient voltages can immediately destroy low-power, solid-state components such as computer chips or weaken them to the point that they fail months after a lightning event.

DOE facilities' vulnerability to lightning was underscored last 


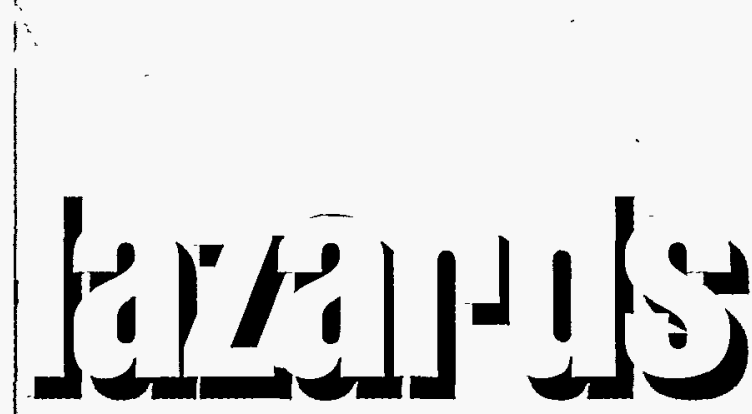

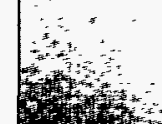

\%

Nisey
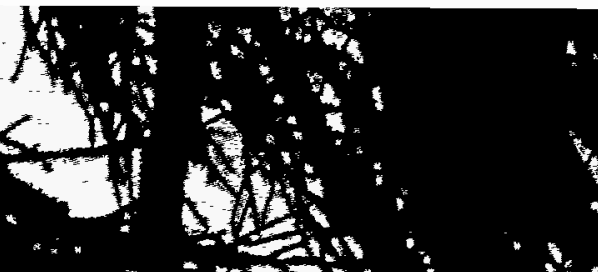

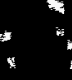

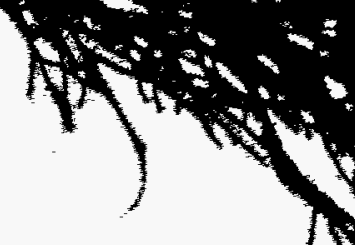

stres.

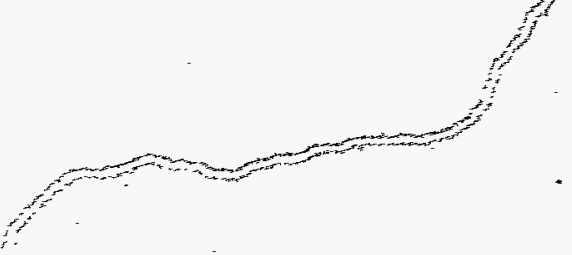

Wis

(1)

summer by Michael Kelly, a high school electronics teacher participating in LLNL's Summer Research Intern Program. Kelly analyzed reports of 365 lightningrelated occurrences at DOE facilities since October 1990 and found that lightning caused a variety of physical damage and alarm system malfunctions. His report draws attention to numerous failures of lightning protection devices, alarm systems, and backup generator systems.

\section{Unified Approach Needed}

No single document presents a unified approach to lightning safety and protection, Hasbrouck notes. The latest version of the U.S. National Fire Protection Association Lightning Standard only briefly references surge suppression. The Standard for Safety Lightning Protection Components recently issued by Underwriters Laboratories provides only general information. What's more, says Hasbrouck, the Department of Defense Ammunition and Explosives Safety Standards are very general and offer neither guidance nor applicable references. The recently released revision of the International Lightning Protection Standard is significantly ahead of U.S. standards.

In response, in 1993 Hasbrouck and fellow engineer Kartik Majumdar proposed developing a guidance document to help DOE managers in assessing the lightning risks associated with any facility and determining the most effective means for mitigating the hazard. That year, the two engineers organized a lightning workshop in Florida sponsored by DOE's Office of Risk Analysis and Technology. Attendees from DOE and its contractors, the Nuclear Regulatory Commission, and other federal government agencies agreed that a comprehensive guidance document on lightning protection was needed as one of a series on natural phenomena hazards mitigation.

Released in draft form in 1995 , it is anticipated that the "Lightning Hazard Management Guide for DOE 


\section{Striking Facts about Lightning}

Cloud-to-ground lightning is the best understood-and most dangerous-type of lightning. It comes in two varieties, positive and negative. Here we will discuss only negative lightning.

As with other types of lightning, negative cloud-to-ground lightning begins when complex meteorological processes, driven by powerful updrafts, cause a tremendous electrostatic charge separation to build up within a thunderstorm cloud. Typically, the bottom portion of the cloud is negatively charged. When voltage levels of about 50 to 100 million volts are reached, air can no longer provide insulation, and electrical breakdowns called intracloud lightning take place within the cloud.

Some 10 to 30 minutes after the onset of intracloud lightning, negative charges called "stepped leaders" emerge from the bottom of the cloud, moving toward the earth in 50-meter-long steps at speeds of 0.03 to $0.07 \%$ of the speed of light (about 100 to $200 \mathrm{~km} / \mathrm{s}$ ). (See the illustration below.) The leaders carry the full voltage of the cloud's negative charge center and create an ionized channel. As the leaders near the Earth, their strong electric field causes streamers of positively charged ions to develop at the tips of grounded pointed objects. These objects may include pine needles, blades of grass, towers, raised golf clubs, and human heads.

These positively charged streamers flow upward under the strong influence of the negatively charged stepped leader. When the distance between a stepped leader's tip and one of the streamers becomes small enough (known as the striking distance, from 30 to 100 meters), the intervening air breaks down and the leader is joined to Earth via the streamer. Now a pulse of current known as a "return stroke" ranging from thousands to hundreds of thousands of amperes moves at one tenth to one third the speed of light $(35,000$ to $100,000 \mathrm{~km} / \mathrm{s}$ ) from Earth through the object from which the streamer emanated and up the ionized channel to the charge center within the cloud, temporarily neutralizing it. An ionized channel remains in the air, and often, additional negative charges, called dart leaders, will quickly move down this path, resulting in subsequent return strokes. It is this multiplicity that causes the flash to appear to flicker. After 30 to 60 seconds, the neutralized center recharges and is ready to produce another flash.

The return stroke's extremely high temperature $(30,000$ kelvin) creates the highly visible lightning channel and instantly turns moisture into steam, producing the associated thunder. The entire event, often consisting of multiple return strokes and typically lasting up to 1 second, is referred to as a lightning flash.

Most direct damage results from the heavy return stroke current that produces a large temperature rise in the resistance of the channel through which the charge travels or from arcing at the point of attachment. When arcing takes place in a combustible or explosive environment, fire or an explosion can result. If the lightning current is carried by an enclosed conductor (e.g., within a jacketed cable, through a concrete wall, or beneath a painted surface), entrapped moisture is turned into high pressure steam, which can cause the cable or painted object to burst, the wall or a tree to explode, or the shoes to be blown off the damp feet of a person struck by lightning.
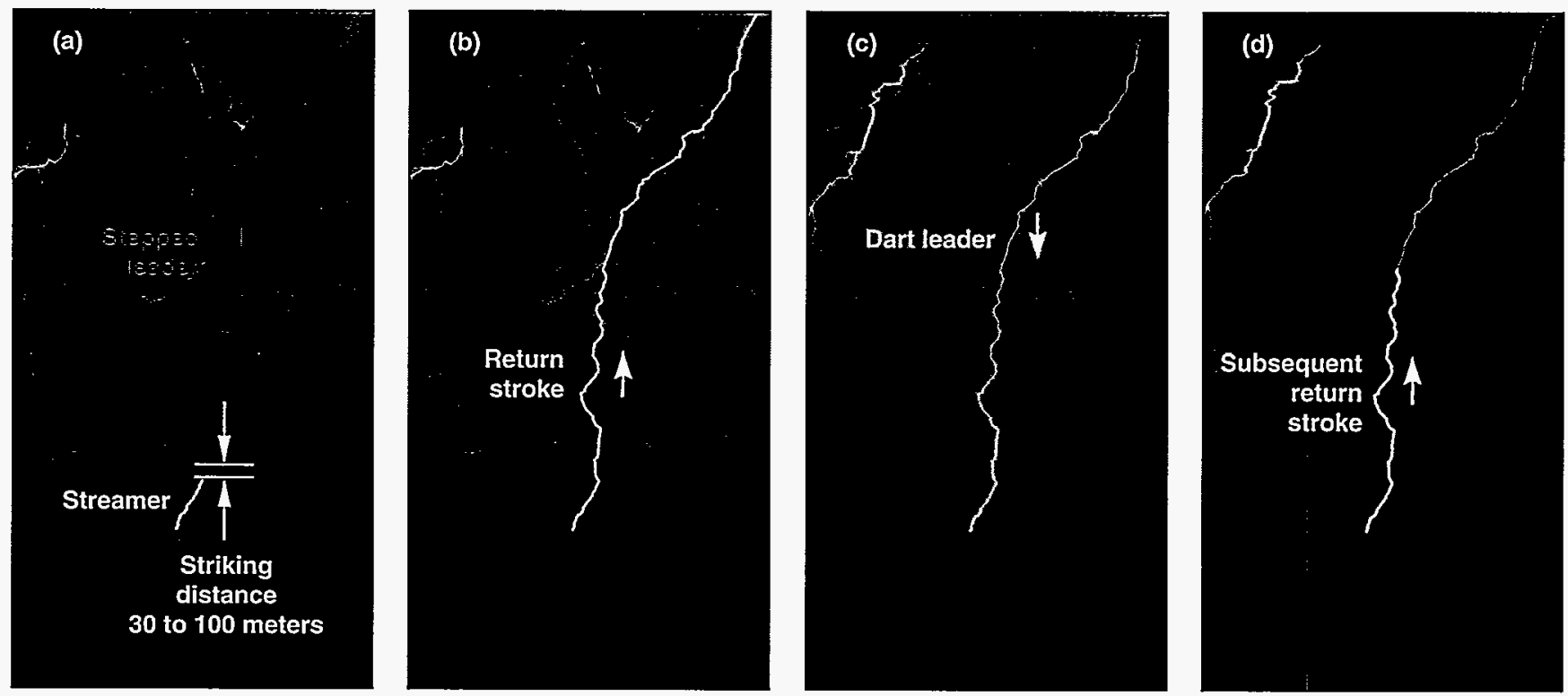

Artist's rendering of a cloud-to-ground lightning flash from (a) development of the negatively charged stepped leader and positively charged streamer through (b) the return stroke followed by (c) a dart leader resulting in (d) a subsequent return stroke. 
Facilities" will be used by new facilities within $\mathrm{DOE}$, other government agencies, and the private sector for determining design requirements as well as for evaluating existing lightning safety and protection systems. ${ }^{1}$

"Lightning Hazard Management Guide" presents a unified approach to lightning safety and protection that combines hazard identification and facility categorization with a new concept-the Lightning Safety System. The Lightning Safety System integrates four lightning safety elements usually addressed as separate topics: a warning system, a warning response plan, a protection system, and a safety system certification plan. Hasbrouck notes that the extent to which each element is implemented at a particular site depends upon the mission of the facility; the element's impact upon the safety of workers, the public, and the environment; and the cost versus benefit of the element's implementation.

"This flexibility allows managers to apply a graded approach in determining the most effective mix of hardware, software, and procedures to solve their particular problem," he says.

Hasbrouck has researched lightning and its effects for more than a decade. He carried out rocket-triggered lightning tests and was responsible for the design of the Lightning Invulnerable Device System to protect nuclear explosive test device systems from lightning. 2,3 He has also written (and presented) a tutorial (Lightning Understanding It and Protecting Systems from Its Effects ${ }^{4}$ ) based on classic texts, current literature, and LLNL experiments.

The work of Hasbrouck and his colleagues is part of a larger LLNL effort to better understand the effects of lightning. Other members of the Laboratory's Defense Sciences Engineering Division have long worked with people in LLNL's weapons program and with experts from Sandia and Los Alamos National Laboratories to ensure that nuclear warheads are protected from lightning (see the box on p. 9). At the same time, LLNL atmospheric investigators have been working to determine lightning's contribution to acid rain. One group is also studying massive, high-altitude, cloud-to-sky lightning-related events called "sprites."

\section{Huge Electrical Discharge}

Hasbrouck explains that lightning is an electrical discharge of immense proportions* that accompanies not only thunderstorms, but also volcanic eruptions, snow and dust storms, and surface nuclear detonations. At the midNorthern latitudes, some $80 \%$ of lightning occurs within clouds (intracloud). About $20 \%$ of all lightning is cloud-to-ground, while an extremely small percentage is cloud-to-sky and between clouds. (Figure 1.)

Cloud-to-ground lightning represents the greatest threat to people, structures, systems, and components. It can be either positive or negative. The vast majority of cloud-to-ground lightning is negative, that is, it transfers negative charge to Earth via a channel-the stepped leader-that emanates from the lower portion of a storm cloud and moves toward the Earth. Once the leader contacts Earth, positive charge moves back up the negatively charged channel, neutralizing it and its source, a negative charge center in the cloud.

During a positive lightning event, on the other hand, a large quantity of positive charge is transferred to the Earth. Negative charges move back up the lightning channel to the thunderstorm cloud, temporarily neutralizing a highly positive-charged region within the cloud. Positive lightning occurs much less frequently than negative lightning and most often toward the end of a thunderstorm, originates in the upper part of a thunder cloud rather than in the lower part, and can be more severe in its effects than negative lightning.

A single lightning event, called a flash, typically lasts for many hundreds of milliseconds (see the box on p. 6); intense thunderstorms can produce several thousand cloud-to-ground flashes. For each discharge, a tree-like streamer (or leader) carries charge toward the ground until the "striking distance" (30 to 100 meters) is reached. The oppositely charged return stroke transforms electrostatic potential energy into electromagnetic energy (radio and light waves), heat, and acoustic energy (thunder).

As delineated in the draft DOE guide, lightning hazard identification considers the severity of the hazard and its likelihood of occurrence. The severity of a flash is defined by the peak amplitude of its return stroke current, its rate of rise, and the amount of charge transferred, while the probability of an object being struck is the product of the local ground-flash density times its lightning-attractive area.

The guide recommends that managers combine a timely and credible threat warning system with suitable lightning protection methods. The waming system should provide an alert when a lightning threat is identified and an alarm when lightning is imminent. A suitable plan for responding to a warning should also be implemented.

Cloud-to-ground lightning occurs randomly, making it impossible to

\footnotetext{
* The average electrical discharge of lightning is about 15 coulombs; the highest charge transfer is estimated to be about 350 coulombs. One coulomb is the equivalent to the electric charge of $6.24 \times 10^{18}$ electrons.
} 
Figure 1. An artist's depiction of the four basic kinds of lightning: (a) cloud-to-sky lightning (sprites), (b) cloud-to-ground lightning, (c) intracloud lightning, and (d) intercloud lightning. accurately predict when and where it will strike. However, lightning announces itself in several ways. A thunderstorm's cloud-to-ground lightning provides some advance warning if its visible, audible, and electromagnetic signals are detected. Ideally, a system designed to acquire and display warnings needs to incorporate one or more direct weather observations, National Weather Service reports (including information from the National Lightning Detection Network), flash detectors, and electric field sensors.

\section{Strikes Are Inevitable}

In the lightning guide, the authors emphasize that despite nonscientific commercial claims to the contrary, the charge in a thunderstorm can be dissipated only by nature's way-the lightning process. Proper lightning protection accepts a strike as inevitable, seeks to provide a controlled path for the current to follow, and minimizes the development of hazardous potential differences.

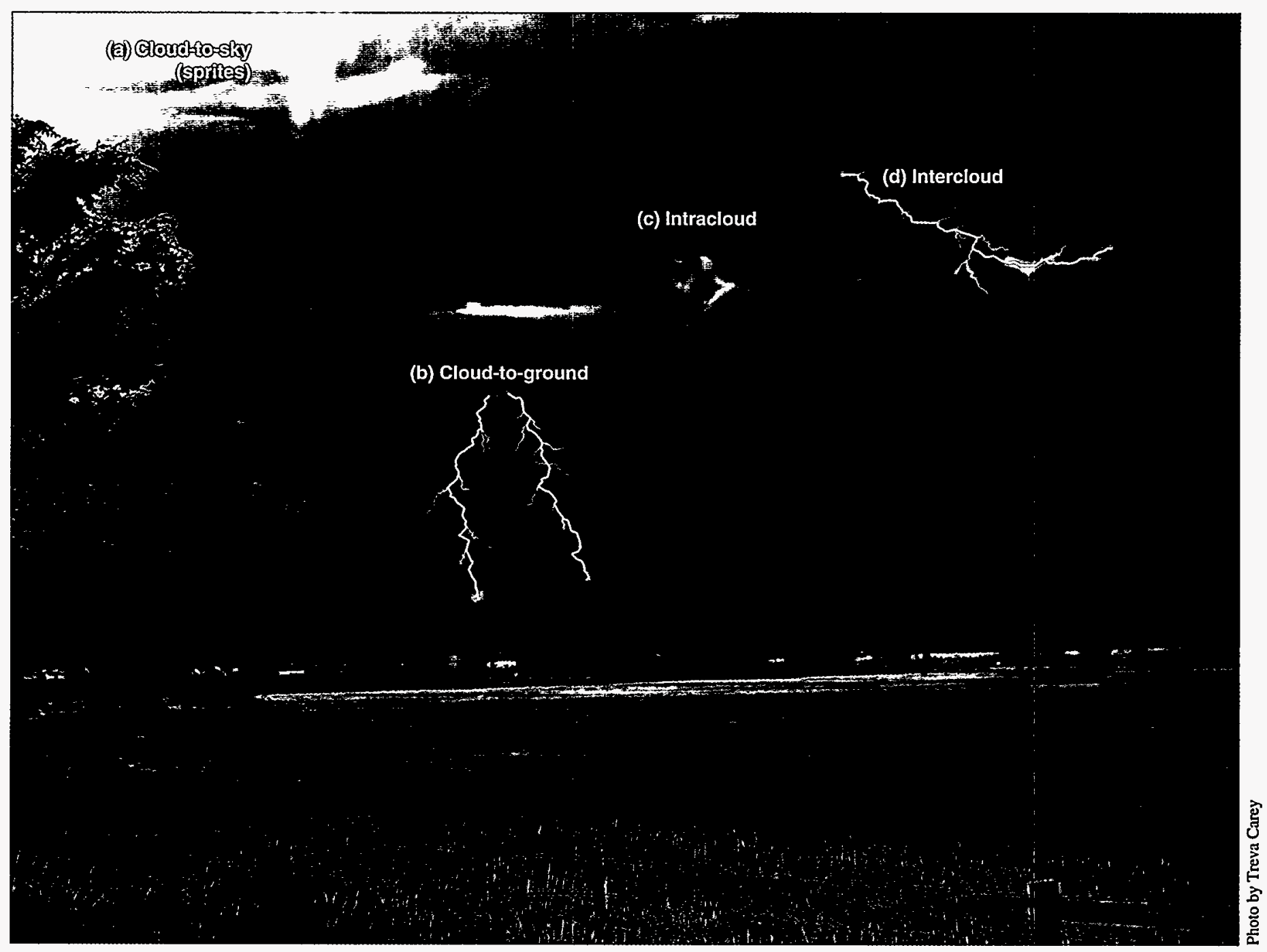


"Lightning is a very-large-amplitude current source," says Hasbrouck. This means that the same amount of current will flow, regardless of whether its path is of low resistance (a metal flagpole) or high resistance (a tree). Much of the energy contained in a lightning return stroke is dissipated as heat in whatever path serves as the current-carrying conductor. A good electrical conductor, e.g., metal structure, will experience little more than minor surface pitting where the current enters and exits. Significant damage can result, however, when poor conductors such as a woodframe building, concrete wall, or tree are struck.

The draft guide presents the "fortress" concept, in which first-level protection of a structure is provided by a lightning grounding system. All electrically conductive paths that penetrate the building (e.g., metallic pipes and vent stacks) are bonded to the lightning grounding system externally at the point of entry. To protect components housed inside, all electrical conductors pass through transient limiters (surge arrestors) located inside the structure as close as possible to the point of entry. Also, limiters are recommended at the power and data input points of individual systems and components.

\section{Using New Testing Methods}

Last year, the document got its first real-world application when Hasbrouck engaged LLNL engineer Richard Zacharias and Richard Collier, an elecromagnetics consultant from EMA Inc. with experience using sweptradio-frequency testing for facility lighting studies, to determine the effectiveness of the lightning protection system of the recently completed Device Assembly Facility (DAF) at the Nevada Test Site. The cavernous DAF

\section{Protecting the Nuclear Stockpile from Lightning}

The U.S. military and space programs have long respected the potential of lightning to damage or even destroy vital weapons components as well as aircraft and spacecraft. Lightning caused the annihilation of a World War I arsenal in New Jersey, it almost turned the Apollo-12 launch into a disaster, it has been responsible for several aircraft crashes, and it led to the destruction of an Atlas-Centaur launch vehicle in 1987, with its $\$ 160$-million payload.

The vulnerability to lightning of today's aircraft and spacecraft is greater than in years past because critical airborne systems employ vast numbers of solid-state components that are susceptible to the effects of a lightning strike as well as the associated electromagnetic fields. In addition, new designs increasingly substitute composite materials for metallic surfaces, eliminating what once was, in effect, a flying Faraday cage, that is, an almost complete metal enclosure that houses the aircraft's electrical and electronics systems.

Lawrence Livermore lightning expert Mike Wilson of Defense Sciences Engineering Division notes that for people residing in the San Francisco Bay Area, home of typically five lightning storms a year, damage from lightning may seem a far-fetched threat.

However, DOE's Pantex plant, located in Texas, experiences about 60 lightning storms annually, and the threat of lightning igniting some of the propellants and high explosives stored at the plant is a real concern. Indeed, DOE considers lightning a particular risk to operations involving the transport, maintenance, and modification of nuclear devices and their associated non-nuclear explosives.

Wilson says that Livermore engineers have been assessing the potential threats from lightning strikes for more than 15 years as part of the Laboratory's mission to assure the safety of nuclear devices. "We're concerned with all environmental threats to the nuclear stockpile," he says. "Lightning has been considered by some people to be an awesome environmental threat from which nothing could survive. But that's not the case. We just need to understand lightning and protect against it."

Ensuring that nuclear warheads and their components can withstand a lightning strike focuses on designing multiple physical barriers that block the transfer of energy from a lightning bolt to critical components and materials contained within a nuclear device. In addition, LLNL engineers use computer models to mimic the electromagnetic fields generated by lightning storms that can affect wiring connected to the high explosives found in every nuclear device. Other models, based on welding computer codes, simulate the effects of direct lightning strikes upon metal.

Another area of research is applying statistics to the threat of lightning to sharpen the estimates of the frequency of lightning strikes. The work is similar to Laboratory risk analyses regarding seismic safety and nuclear power plants.

When underground tests were being planned and conducted at the Nevada Test Site, Laboratory test personnel always kept a watchful eye on the weather. Instruments monitored atmospheric electrification, and the U.S. Weather Service operated a cloud-toground lightning locating system. During the late 1980s, the Laboratory Test Program adopted a lightning protection method designed by LLNL engineer Richard Hasbrouck that took advantage of the fact that the nuclear device system was contained within a steel enclosure. In Hasbrouck's design, called the Lightning-Invulnerable Device System, the explosive device and associated components reside within a "fortress," a closed, metallic surface connected to another grounded conductor similar to a Faraday cage. The design was validated through tests that first used simulated lightning at the Lightning Transient Research Institute in Miami Beach, Florida, and later rocket-triggered lightning at NASA's Rocket-Triggered Lightning Facility at the Kennedy Space Center.

The comprehensive lightning appraisal of the Device Assembly Facility at the Nevada Test Site discussed at the left was designed by Laboratory personnel. The appraisal identified weaknesses in the facility's lightning protection system through the use of a state-of-the-art swept-radio-frequency testing procedure. 
Figure 2. One of several flashdensity maps in the area of the Device Assembly Facility (DAF) at the Nevada Test Site in southern Nevada used to arrive at a strike probability estimate. The DAF is at the center of the map. was originally designed to safely and securely house nuclear test device assembly activities and will be available to support DOE Defense Programs stockpile stewardship activities. Its roof, rear wall, and much of its side walls are earth-covered.

The concepts presented in the new guidance document were used to evaluate the DAF's lightning safety systems. In conducting the study, the review team focused on the main reinforced concrete structure, not the facility's peripheral outbuildings.

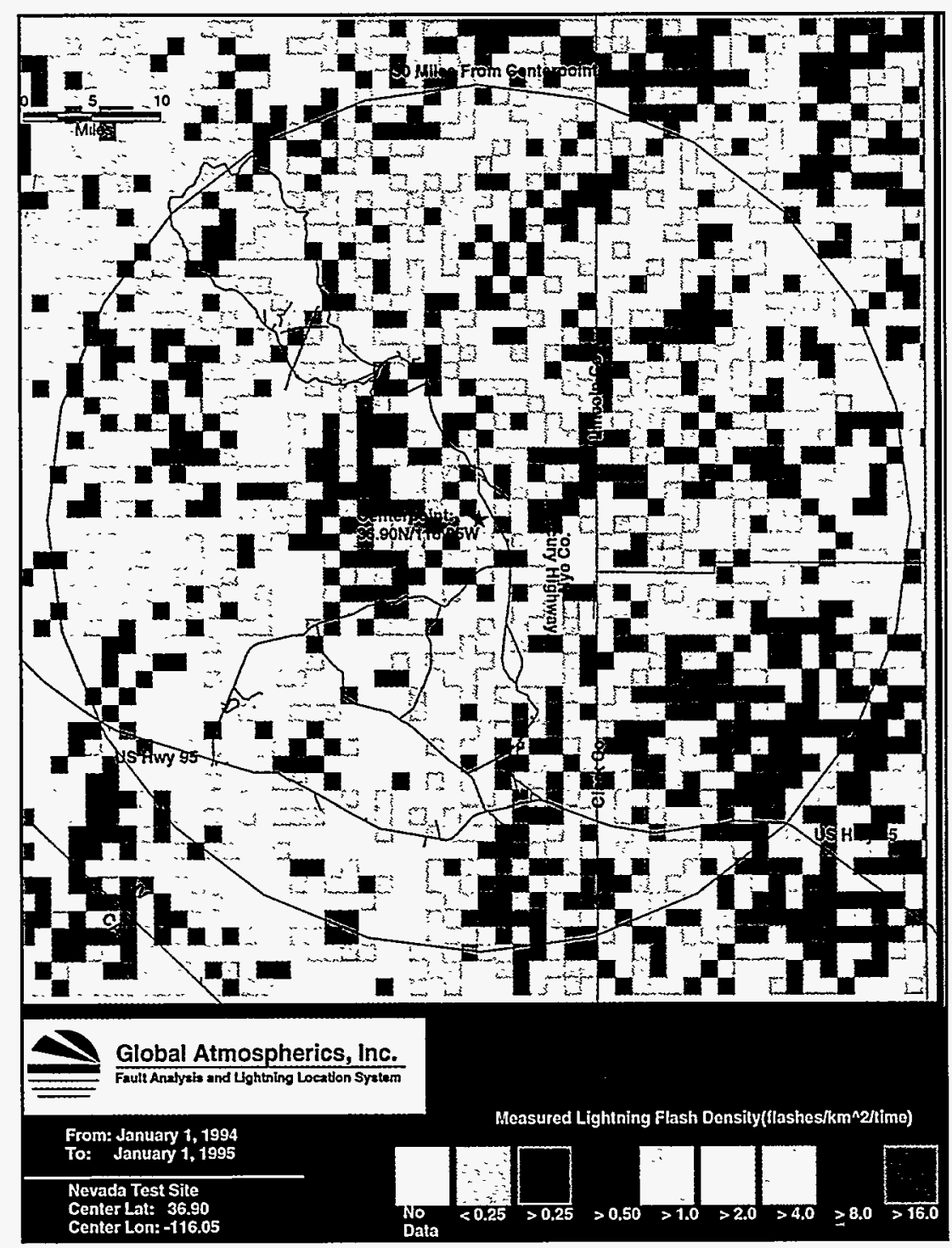

Traditional measurements showed that the DAF structure exhibited a low value of direct current resistance, not surprising because it contains a very large quantity of interconnected metal in good contact with the Earth.

However, was it immune to lightning damage? To find out, the team went a step further and conducted an electromagnetic survey, consisting of low-level radio-frequency testing to determine lightning's likely penetration of the structure. (See the box on p. 11.)

The testing at DAF revealed that small to moderate amounts of lightning current could enter the interior via metallic paths provided by objects such as the vent stacks and antenna feedlines that penetrate the roof top. These findings are helping facility managers evaluate additional protective measures for the facility.

The study confirms that cloud-toground lightning represents a natural phenomena hazard in the DAF environment and estimates that lightning will strike some point of the facility about once every 20 years. This figure was arrived at by multiplying the ground-flash density at DAF, which is based on five years of actual NTS lightning strike data (Figure 2) and the lightning-attractive area of the DAF. If the DAF were entirely underground, its ground-surface area would be the lightning-attractive area. However, lightning-attractive area increases with object height.

Consequently, the twelve 39-meter-tall metal light poles around the DAF's perimeter are most likely to be hit by large-to-severe amplitude strokes (greater than about 40 kiloamperes), while smallto-moderate ones are more likely to strike the structure.

An unexpected outcome of the analysis showed that a large peakamplitude stroke to a light pole will produce essentially the same effects within the DAF structure as a small stroke attached directly to a point on 


\section{Low-Level radio-frequency testing at the Device Assembly Facility}

Low-level radio-frequency (rf) testing was done on the Device Assembly Facility (DAF) at the Nevada Test Site to test the effectiveness of the DAF's lightning protection system. The block diagram below shows an assembly room at DAF outfitted with the rf testing system. The permanent DAF structural elements are in green; the testing system components are red.

During If testing, the network analyzer continuously emits a signal over the range of $10 \mathrm{kHz}$ to $30 \mathrm{MHz}$, representing (approximately) the rf spectrum of a lightning stroke. The analyzer's output signal travels through coaxial cable to the 50-watt amplifier located on the DAF's roof. The amplified signal then proceeds to an injection coil and through the test injection cable to lightning grounding system downconductors connected to two of the facility's metal vent stacks. These vent stacks are interconnected by means of the lightning grounding system's rooftop conductors. Such rooftop penetrations are unintentional electrical conductors, allowing lightning currents to enter the DAF. Various conductive paths inside the DAF, e.g., bonding and/or mechanical attachments, electrically connect the vent stacks to the DAF's steel rebar and the facility's lightning grounding system.

As the rf signal travels to the downconductor, it passes through a sense coil, which sends a sample of the applied signal back to the network analyzer. Because the injection cable will alter the rf signal, this sample provides the network analyzer with the characteristics of the signal being applied to the stack. The applied test signal will divide, with some portion flowing on the lightning grounding system conductors and some entering the DAF via the vent stack.

In the configuration shown, the testing system's measurement coil detects that portion of the applied signal flowing on the copper vacuum line and sends it to the network analyzer. The network analyzer compares this signal's characteristics to those of the applied signal sampled by the sense coil. The personal computer is used to analyze and archive the data. Later, this low-level data is scaled up to levels associated with a lightning strike, allowing modeling of worstcast lightning effects on the facility to determine the adequacy of the facility's lightning protection system.

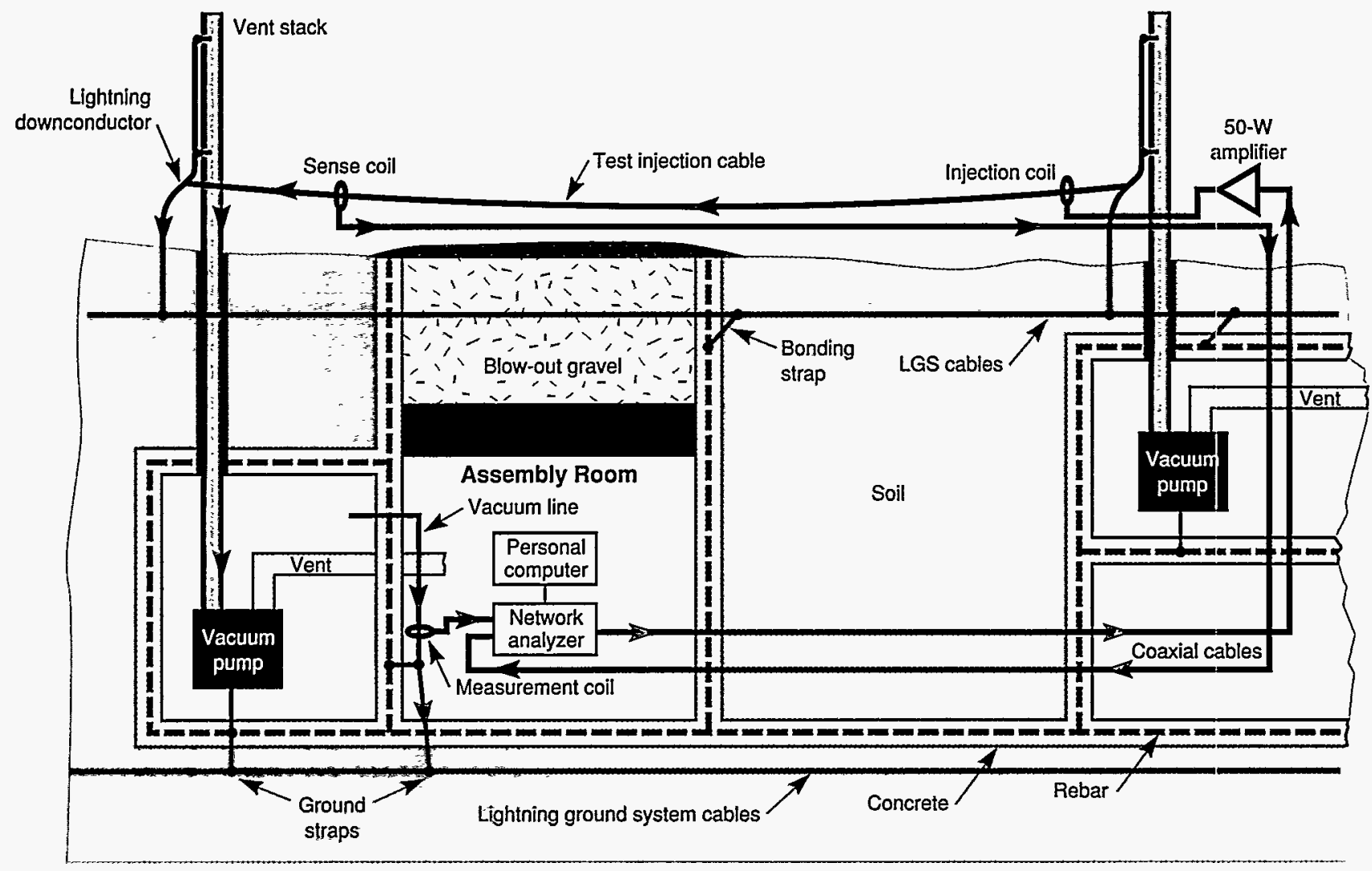


the structure's roof. The poles, therefore, are expected to effectively divert large-to-severe amplitude return strokes away from the numerous rooftop points of entry.

Hasbrouck is gratified that the DAF lightning study provided an opportunity to apply the concepts put forth in the guidance document. By employing radio-frequency penetration testing, it was possible to identify how and how much lightning energy would leak through "holes" in what the lightning protection code would have judged to be a solid facility. He notes that a 1993 lightning study of DOE's Pantex facility also recommended that some form of penetration radio-frequency testing be carried out in the future.

"Lightning knowledge," he emphasizes, "is neither archaic nor arcane. We cannot prevent lightning, but knowledge of it can help us enhance safety, protecting us and costly property against its damaging and potentially catastrophic effects."
Key Words: hazard management, lightning, radio-frequency testing.

\section{References}

1. R. T. Hasbrouck and K. Majumdar, Development of a Guidance Document for Lightning Protection of DOE Facilities, Lawrence Livermore National Laboratory, Livermore, CA, UCRL-JC119983 (1995).

2. R. T. Hasbrouck, et al., Final Report of the Nuclear Explosive Lightning Vulnerability Task Force, Lawrence Livermore National Laboratory, Livermore, CA, UCRL-15618 (1984).

3. Richard T. Hasbrouck, et al., Final Report for the Device Systems Lightning Project, Lawrence Livermore National
Laboratory, Livermore, CA, UCRL-21068 (1988).

4. R. T. Hasbrouck, LightningUnderstanding It and Protecting Systems from Its Effects, Lawrence Livermore National Laboratory, Livermore, CA, UCRL-53925 (1989).

For further information contact

Richard Hasbrouck (510) 422-1256

(hasbrouck1@IInl.gov) or

Kartik Majumdar (510) 422-5060

(majumdar1@IInl.gov). For information on the Device Assembly Facility study, contact Richard Zacharias (510) 423-0714 (zacharias1@IInl.gov).

\section{About the Engineer}

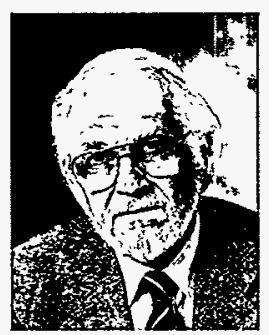

RICHARD HASBROUCK holds a B.S. in electrical engineering and is a Registered Professional Engineer in California. He joined the Laboratory in 1968 and is currently a senior electronics engineer. During his career at Lawrence Livermore, he has supported various projects in the test program. Involvement in nuclear explosive safety studies led to his study of lightning safety, culminating in the lightning hazard management concept. He has written numerous papers and reports on this subject and is co-author of the draft "Lightning Hazard Management Guide for DOE Facilities" (1995). Hasbrouck is a consultant and co-director for engineering of the National Lightning Safety Institute.

In a collateral Laboratory assignment, he is the aviation project officer responsible for the aviation safety interface between Lawrence Livermore and the DOE on Laboratory projects related to aviation, and he was general manager of the Laboratory's F-27F aircraft operation. Prior to joining the Laboratory, he designed, tested, and fielded electro-optical, instrument servomechanisms for astronaut training simulators produced by Farrand Optical Co. in New York for NASA's Project Apollo. 


\section{Groundwater Model
More Bost-Efleotive Bloanup by Dasign}

Computer modeling is proving

its usefulness as cleanup of

contaminated groundwater

proceeds at the Livermore

site. Modeling is an extremely

effective tool for deciding where

and how groundwater remediation

efforts should be directed. Our models are

being made available to others for more

efficient remediation around the country.

Q

ROUNDWATER modeling uses mathematical methods to help scientists "see" what is happening underground, to make up for what we cannot see with our own eyes. The discipline of groundwater modeling has been around for at least 25 years, but with the powerful desktop computers and advanced software available today, computational modeling is an easier and more effective task than it used to be, Evaluation processes that used to take days or even many weeks can now be done in minutes and often with a higher degree of accuracy.
We have developed several new software tools that can be used by groundwater remediation planners anywhere. MapIt, for example, can read a variety of one-, two-, and threedimensional data sources and will allow remediation planners to rapidly produce input files for the various simulation codes. With MapIt, we have reduced the time needed to regrid and execute new three-dimensional conceptualizations from months to hours. In the past, a different "code preparation" program was required for each groundwater simulation code.
Another tool is PLANET, an easy-touse, point-and-click, drag-and-drop program that replaces laborious, manual operation of modeling codes to evaluate alternative remediation scenarios

(Figure 1). Using these and other newly developed tools, groundwater scientists or engineers at Lawrence Livermore National Laboratory and elsewhere can quickly prepare and simulate robust three-dimensional conceptual models of our site.

We now have the ability to simulate groundwater flow and transport in a large number of possible configurations 
Figure 1. PLANET, graphical user interface software we have developed, can be used by groundwater remediation planners at any site to examine various contamination extraction and injection scenarios. This two-dimensional simulation of a possible cleanup scenario for the Livermore site shows how concentrations of volatile organic compounds would decline over time. of a collection of wells (known as a well field) used to extract contaminated groundwater from the subsurface. This ability is a key to finding an optimal remedial system design or designs. Conventional methods of formal optimization can practically consider only a few hundred simulations of possible well field configurations, whereas thousands or even millions of possible configurations are needed to find the most effective designs. As a result, the use of conventional formal optimization methods seems impractical and in need of a new approach.

New methods enable us to quickly evaluate millions of prospective engineering designs and optimize remediation pumping strategies. These methods use artificial neural network (ANN) technology to process a much smaller set of simulations, repeatedly, for any and all configurations. ANNs, whose development was inspired by studies of the human brain, can be "trained" to predict the cost, extracted mass, and containment information that a model simulation normally generates. ANN speed is remarkable-the technology can evaluate thousands of well configurations per second. With ANNs to repeatedly predict outcomes for a particular well field, a genetic algorithm, inspired by evolutionary concepts such as natural selection, directs the search for the best well fields to meet remediation goals.
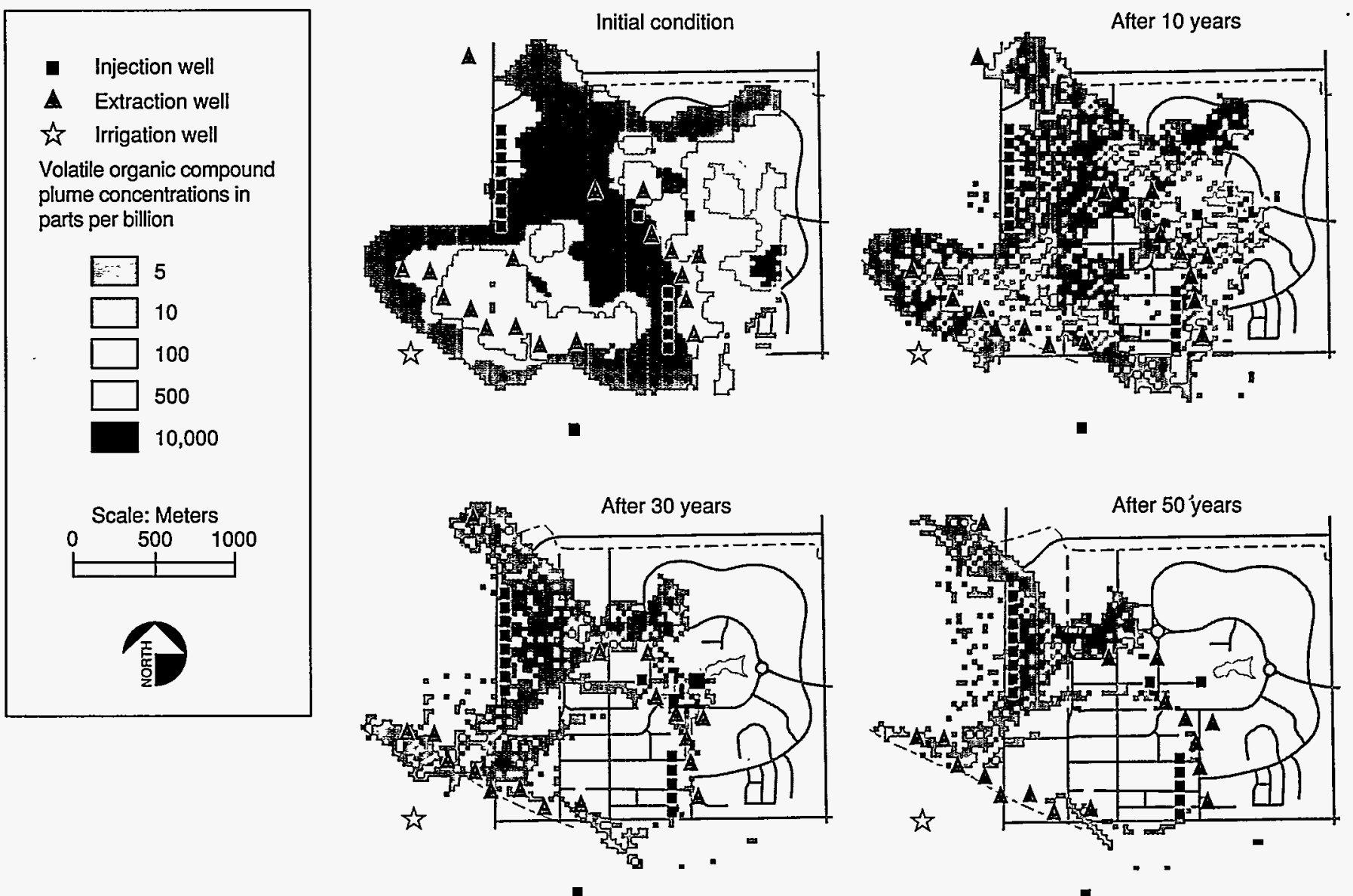
Scientists at Lawrence Livermore have been developing and using advanced numerical modeling techniques for decades because the design of nuclear weapons requires extensive modeling prior to testing. It made sense, when groundwater contamination was discovered, for our in-house researchers to continue modeling, albeit this time with a very different goal.

\section{Why We Model}

We have known since 1983 that there are contaminants in groundwater beneath the Livermore site. (See the box on top right.) But we can only see the soil and water beneath the Laboratory in small, drilled samples of soil and in water samples taken from monitor wells. Because we cannot take core samples of the Laboratory's entire subsurface or cover the site with monitor wells, there are large gaps in our data.

How have we determined the best way to clean up this uncertain environment? And how long it will take? As described in the box on the bottom right, groundwater modeling allows scientists to develop a picture of the workings of an otherwise invisible subsurface. Using computer simulations of the flow and movement of groundwater contaminants, we can evaluate the migration rates and paths of contaminants in groundwater and soil, assess potential health risks, select extraction and injection well locations, and optimize hydraulic control and contaminant removal in our remediation designs.

Modeled simulations of groundwater behavior have served as an effective decision-support tool for Laboratory scientists and engineers in our efforts to clean up contaminated groundwater at the Livermore site as quickly and inexpensively as possible. Modeling provides a means of rapidly retrieving

\section{Groundwater Contamination at the Laboratory}

The contamination at the Livermore site consists of widely distributed plumes of several volatile organic compounds (VOCs), tritium, fuel hydrocarbons, and some heavy metals. Some of this contamination has traveled in groundwater off site, especially on the south and west sides of the Livermore site. Contamination was discovered in 1983, and Livermore was declared a Superfund site in 1987.*

The standard method for handling groundwater contamination is to extract the contaminated groundwater and treat it. Known as "pump and treat," this method is very slow. Laboratory scientists have therefore seized the initiative to develop fast, inexpensive, innovative site restoration technologies that can also be applied elsewhere and to demonstrate these technologies at a Superfund site. Restoration activities at the Laboratory to date have centered on a smart pump-and-treat philosophy that includes detailed characterization, validated modeling, phased implementation of remediation, directed extraction, and adaptive, time-managed pumping. The Laboratory has also used underground steam stripping, electrical heating, and vacuum extraction methods to treat the gasoline contamination. Other technologies being studied include abiotic, microbial, and thermal oxidation.

In late 1995, environmental regulatory agencies declared soil cleanup above the water table to be complete at the site of an underground gasoline spill. This is the first formal regulatory closure of a nonexcavation cleanup activity at the Livermore site since cleanup began in 1988 .

* Site 300 , an area east of the Livermore site that has been used since 1953 for testing non-nuclear, high-explosives compounds, was also declared a Superfund site in 1990 . However, all discussions in this article are related to groundwater modeling and remediation at the Livernore site.

\section{What Is a Model?}

A conceptual groundwater model begins as a collection of information about the system's material properties. That information then becomes a mathematical description of an existing groundwater system, coded in a programming language, together with a quantification of the system's boundary conditions, parameters, and internal sources and sinks of groundwater and contaminants. Sometimes confusingly, the computer code used to simulate the groundwater system is also referred to as a groundwater model. So the word "model" is sometimes used for the description of the system under study and sometimes for the computer code that generated the description.

Groundwater modeling is a process of mathematically analyzing the mechanisms and controls of groundwater systems and the policies, actions, and designs that may affect these systems. Models help researchers understand subsurface fluid flow and fluid-related mass-transfer and transformation processes. They are also of use in analyzing the responses of subsurface systems to variations in both existing and potential new stresses, e.g., pumping out contaminated groundwater or returning treated groundwater to the subsurface. Modeling is an effective tool for screening alternative remediation technologies and strategies; the resulting "what-if" simulations are helpful for finding the most efficient, cost-effective methods for remediating groundwater contamination. By looking at many variables in various combinations, modeling sometimes point the way to nonintuitive ways that complex systems respond to stress and may, thus, lead to new well field designs and remediation strategies. 
and analyzing a variety of data, and as modeling methods have become more sophisticated, models have been the key to refining the scope of the cleanup work. Cleanup efforts can be targeted more precisely, thereby reducing the scope of the project and saving both time and money.

Table 1. Estimated cleanup time decreases as the realism of our conceptual models improves*

\begin{tabular}{|c|c|c|c|}
\hline & $\begin{array}{l}\text { Simple } \\
\text { "Tank" Model }\end{array}$ & $\begin{array}{l}2 \cdot D \\
\text { CFEST Model }\end{array}$ & $\begin{array}{l}3-D \\
\text { CFEST Model }\end{array}$ \\
\hline Date & 1990 & $1992-1994$ & $1995-1996$ \\
\hline $\begin{array}{l}\text { Time to MCLs } \\
(5 \mathrm{ppb})\end{array}$ & 80 years & 75 years & Approximately 30 years \\
\hline $\begin{array}{l}\text { Time to risk-based } \\
\text { remediation ( } 25 \mathrm{ppb} \\
\text { assumed for this } \\
\text { example) }\end{array}$ & 35 years & 40 years & 10 to 15 years \\
\hline \multicolumn{4}{|c|}{$\begin{array}{l}\text { "Applies to remediation of volatile organic compounds in distal contaminant plumes whose source of } \\
\text { contamination has been controlled. }\end{array}$} \\
\hline
\end{tabular}

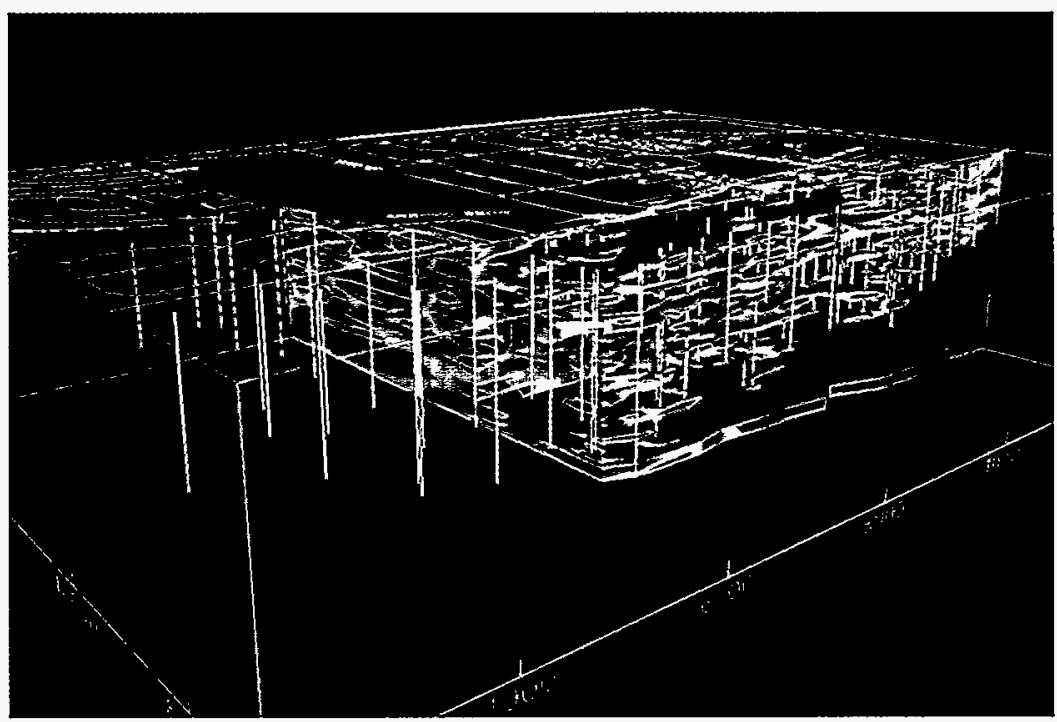

Figure 2. This visualization of core sample data represents part of the first step in developing a conceptual model. Subsurface connectivities, which show how groundwater moves, have not yet been developed in this step.
For example, in 1987 when the Laboratory was placed on the Superfund list, little modeling had yet been done. Our early simulations using a very simple model indicated that if we took no action to remediate the contamination, volatile organic compounds would spread throughout the Livermore basin in 500 to 800 years and become sufficiently diluted as to no longer be a problem. However, this "no action case" precluded many uses of the groundwater in the Livermore basin during that time period.

Subsequent modeling efforts, which have improved in their physical realism over time and are based on remediating the contamination using the latest cleanup technologies, have reduced the time frame considerably, as shown in Table 1. Today, using state-of-the-art, threedimensional modeling, a risk-based approach to groundwater cleanup, and accelerated cleanup of source regions, we can greatly reduce the estimate for successful remediation of contamination.

\section{Conceptual Modeling}

The first step in the modeling process is to develop a conceptual model, which is the initial representation of the subsurface, including both the saturated and unsaturated groundwater zones. This conceptual model incorporates all field data and laboratory meásurementsa huge quantity of material. At Livermore, hundreds of monitor wells both on site and off provide information about groundwater elevations and contaminant concentrations, distribution, motion, and natural degradation. Thousands of core samples provide geologic data. We have extensive geophysical logging and seismic information, data on geochemical properties and reactions underground, and information about quantities of contaminants removed by groundwater pumping at extraction 
wells, by dynamic steam stripping, and by soil vapor extraction above the water table (Figure 2).

But even with all this characterization information to apply to the conceptual model, data are still insufficient to generate a highly resolved conceptual model for groundwater remediation because the subsurface is not uniform. For instance, a core sample taken at point $A$ indicates soils with hydraulic conductivity, diffusion, and absorption properties that are very similar to those of a core sample taken at point $B$, 30 meters away. The soils between those two points may or may not be similar. Soils have been laid down and rearranged unevenly over millennia, and tiny fingers and braids of different soil types intermingle. Each type of soil has different, nonuniform properties that govern how quickly or slowly contaminants can travel through that soil.

A time-honored method of making up for missing data is to interpolate. Another method of filling in these data gaps is inverse modeling, a mathematical method of backing into missing data, which is used in many scientific disciplines where a lack of detailed data is a problem. Measured patterns of groundwater flow and contaminants transmitted through the Earth's subsurface can be used to back-calculate soil properties with a variety of inverse solution methods.

The conceptual model, which relies in part on interpolated data, also incorporates hydrostratigraphic analysis, a process described in the January/February 1996 issue of Science \& Technology Review. ${ }^{1}$ Hydrostratigraphic analysis integrates chemical, hydraulic, and geologic data and includes exhaustive trend analyses performed to produce a map of subsurrface connections that indicates where contaminants can and cannot travel. Hydrostratigraphic analysis was borrowed from the oil and gas industry where it is used to determine the best way to exploit underground reserves. It is fairly new to groundwater modeling but has proven to be an effective tool in the modeling process.

This composite of actual and interpolated or back-calculated data is used to create the conceptual model in a mathematical description, or modeling code, that simulates what is happening in the subsurface. But the conceptual model is still not final because many valid interpolations are possible. So the next step is to test the model and calibrate it. As new field data become available, they are compared with the modeling code simulations. If the simulations do not match reality, then the conceptual modeling process continues until simulated and field data come into agreement. This calibration part of the modeling process, known as circular modeling, is essential to develop the best picture possible of how the subsurface behaves (Figure 3 ). (a)

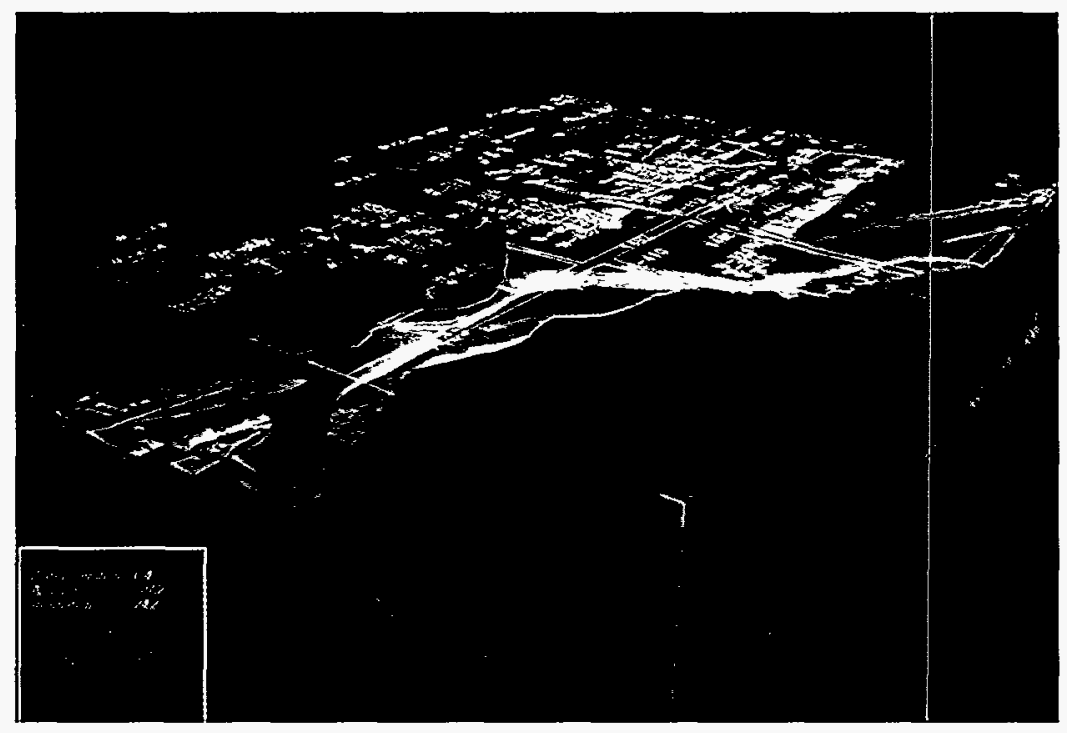

(b)

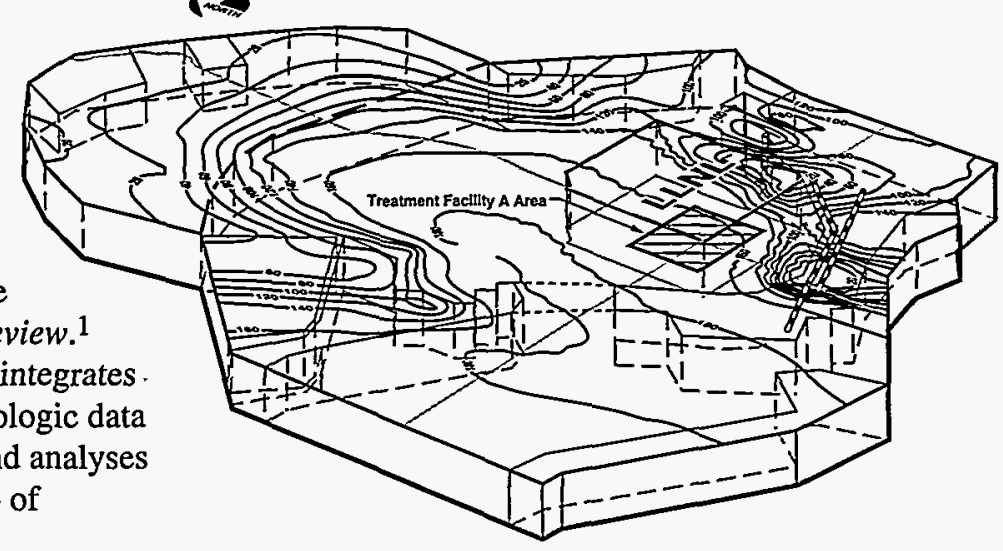

Figure 3. (a) The threedimensional conceptual model of the hydrostratigraphic units around Treatment Facility $A$ in the southwest corner of the Livermore site shows the underground streambeds through which groundwater moves. The three-dimensional model presents considerably more information about the subsurface than does (b) the two-dimensional model of the Livermore basin. 
Figure 4. We used the threedimensional CFEST modeling code to forecast the decline in concentrations of perchloroethylene (PCE), a volatile organic compound, beneath Treatment Facility $A$ (TFA) in the southwest corner of the Livermore site. The decline shown in the simulations at the right for the years 1995, 2009, and 2026 assumes that the source of contamination for this distal contaminant plume has been controlled and that "smart" pump-and-treat cleanup methods continue for the duration. The PCE mass removed in these three dimensional simulations agrees closely with measured PCE removal.
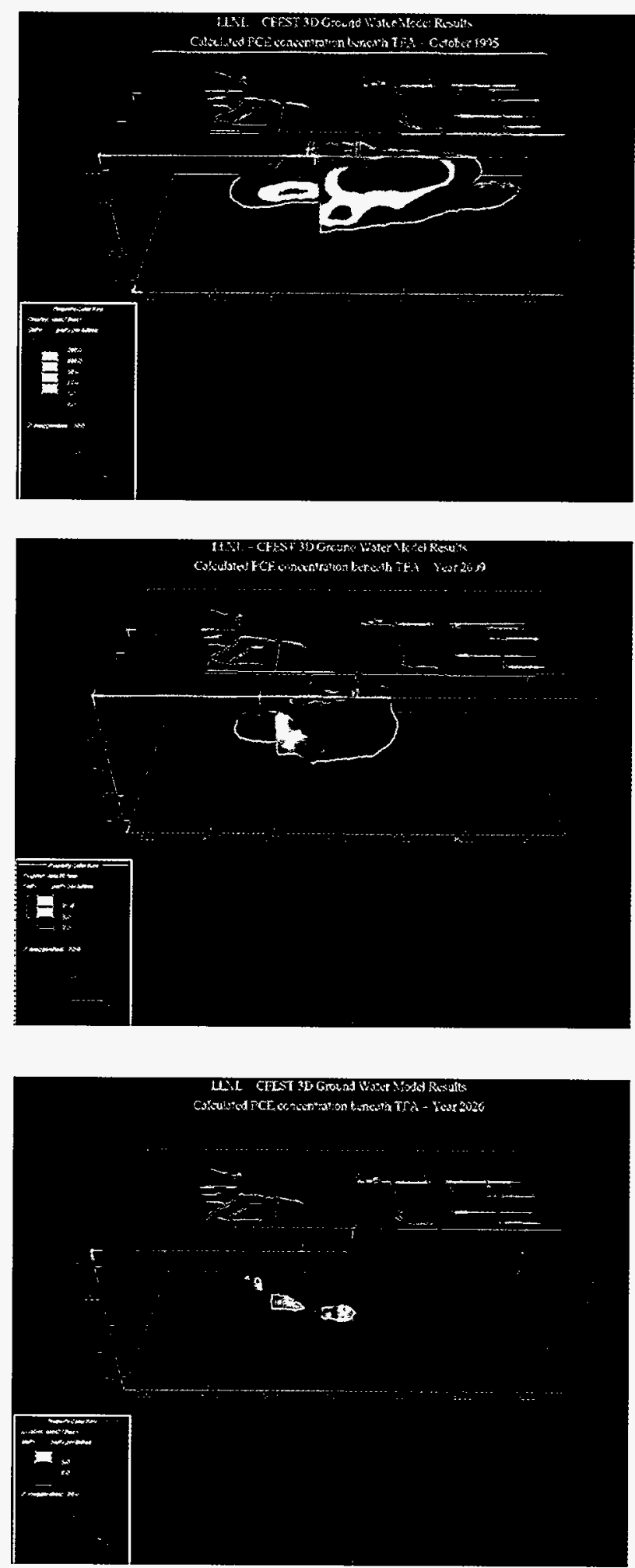

\section{Forecasting the Future}

Groundwater modeling is very useful for estimating what will happen to the subsurface in the future (Figure 4). What will the contaminant plumes look like and where will they be in 10,30 , or 100 years if we do nothing? If we do make efforts to remediate the contamination, how will the underground environment respond to manmade changes in the subsurface? What will happen to the contaminant plumes when groundwater is pumped out? What will happen to the surrounding soils and groundwater? Is it beneficial for the cleanup effort to return treated groundwater to the subsurface? Will fuel hydrocarbons degrade naturally without posing unacceptable risks to Laboratory personnel and the public? Where should additional wells be located and what should be the rates of extraction and injection? And most important: how long will it take to clean up the groundwater to meet regulatory requirements?

Modeled simulations with the calibrated conceptual model can be very effective in helping to answer these questions. The more accurate the calibrated conceptual model, the more accurate the model forecast simulations will be.

\section{From 1-D Models to 3-D}

Simple questions about the subsurface can often be answered using dimensionless or one-dimensional conceptual models. Two-dimensional conceptual models, on the other hand, provide a better framework for organizing and relating geologic, hydrogeologic, and chemical information. Two-dimensional models give scientists, the public, and regulators a more realistic picture of the general 
behavior of flow and contaminant migration processes; remediation optimization and risk analysis issues are more visible; the importance of degradation and reaction processes ismore evident; and cleanup times and capture zones can be estimated.

But because our world has three dimensions, two-dimensional models have their limitations. In twodimensional models, vertical variations in contaminant concentrations and soil hydraulic properties are averaged out, potentially overestimating the time necessary to clean up a site (Figure 5). In groundwater remediation, time equals money, so overestimating time also means running up the cost of the cleanup with untargeted well field designs and perhaps wasting taxpayer dollars.

Three-dimensional conceptual models are traditionally timeconsuming and costly to implement manually in groundwater modeling codes, but with new software tools, we have made considerable advances in their use. Because three-dimensional models are more representative of the real world, we can incorporate threedimensional hydrostratigraphic representations and more effectively assess cleanup strategies, costs, and impacts. Wells can be targeted for cleanup of specific volatile organic compounds (VOCs). Three-dimensional modeling can also be used to develop targeted implementation strategies for such new technologies as dynamic underground stripping, abiotic reduction, and microbial filters.

\section{Laboratory Innovations}

The Laboratory has initiated a number of significant developments in groundwater modeling. For example, we use a variety of simulation modeling codes, each of which has its own "mesh" system for accepting such conceptual model data as conductivity, thickness, and hydraulic head. The mesh frequently must be modified to improve accuracy in simulations, to modify the conceptual models, and to resolve remediation-stressed conditions. Manually translating, or "mapping," conceptual model data to a particular mesh was a very tedious, timeconsuming process and one that was prone to error, even for twodimensional models. With threedimensional models, mapping onto millions of mesh nodes would be almost impossible without electronic tools. While some mapping tools did exist, they were designed to be used with a specific modeling code and allowed for little geological complexity.

As a result, Lawrence Livermore is developing MapIt, which can map all conceptual model data onto any mesh so that it can be used by virtually any
Figure 5. A two-dimensional simulation using the CFEST modeling code underestimated the total volatile organic compound (VOC) mass that would be removed at Treatment Facility $B$, which is on the west side of the Livermore site. The three-dimensional simulation predicted that by April 1995, we would have removed approximately $3.25 \mathrm{~kg}$ of VOC mass whereas we had in fact removed over $10 \mathrm{~kg}$ from the actual three-dimensional subsurface.

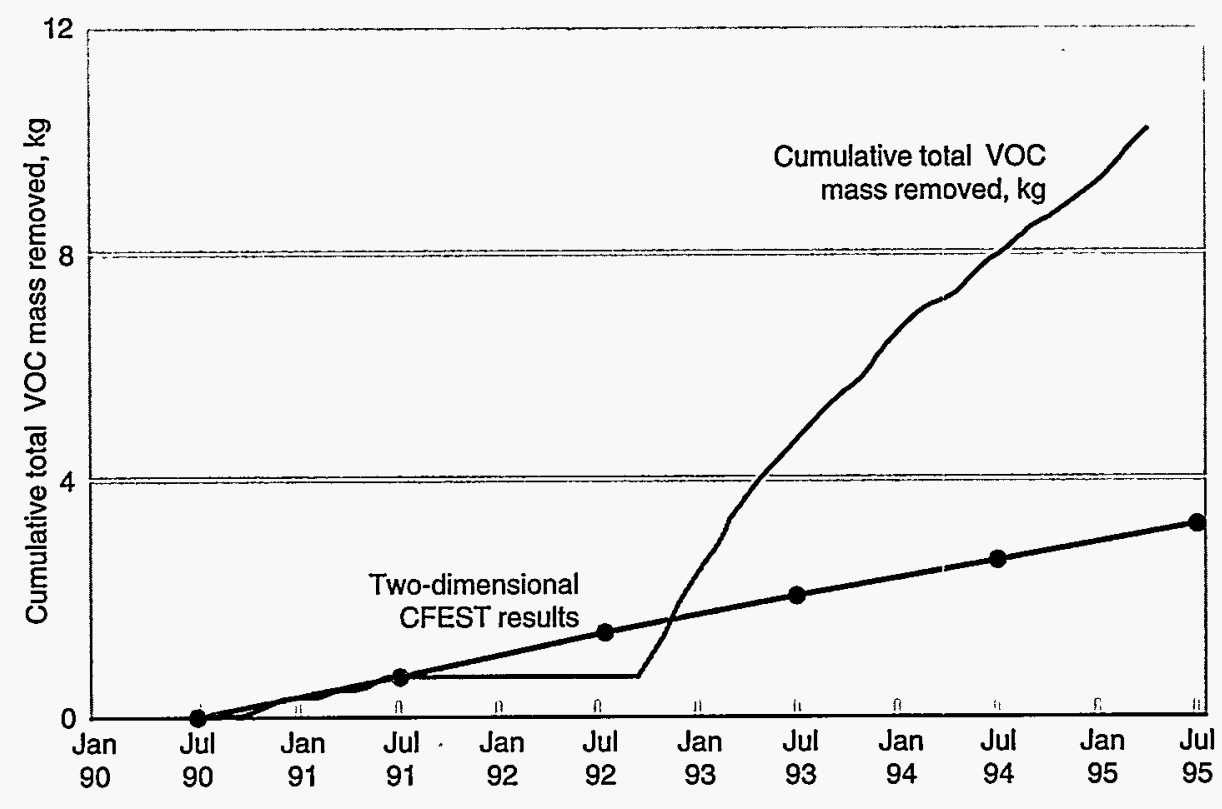


Figure 6. The huge number of nodes on the mesh for the three-dimensional conceptual model of the Livermore basin illustrates the usefulness of Maplt for mapping conceptual model data to a mesh. Mapping soil conductivity, thickness, hydraulic head, and other data by hand to those nodes would take months if it were done manually. With Maplt, a new three-dimensional conceptualization of a site can be created in just a few hours.
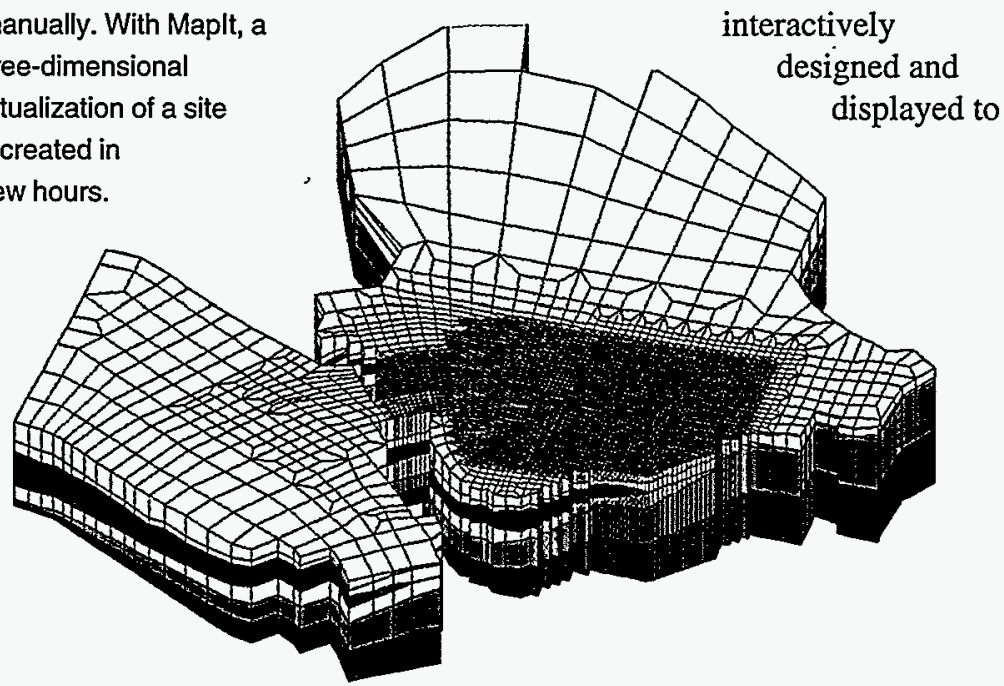

modeling code (Figure 6). Two modeling codes that use different mesh systems can now be used for simulations using the same conceptual model data, and they can then be compared in more meaningful ways. MapIt includes a "feature" database that provides for considerable geologic complexity. MapIt is easy to use and allows the user to view and manipulate the features in the conceptual model as well as the graphical representation of the simulation model. Another benefit of MapIt is its use of an electronically encoded, time-stamped conceptual model, which encourages the use of consistent conceptual models across all modeling efforts.

We have also developed PLANET (Pump Layout and Evaluation Tool), an interactive software package that gives environmental remediation planners at any site the ability to quickly evaluate a large number of remediation scenarios as part of an overall strategy of hydraulic management. PLANET provides a simple, site-map-oriented interface to industry-standard flow-andtransport modeling codes. Within PLANET, a series of chemical transport simulations can be interactively designed and displayed to

examine the migration of existing contaminant distributions in the saturated zone, under natural conditions, as well as under various proposed remediation scenarios. PLANET can be adapted for use with either two-dimensional or threedimensional modeling codes.

Artificial neural networks allow us to make use of optimization techniques that were not possible in the past because the evaluation of thousands of alternatives was so time consuming. ANNs' ability to evaluate thousands of designs per second compares to the 3 to 4 hours that a modeler normally requires to simulate a single design at a common Unix workstation not equipped with ANNs. In a small-scale trial of the ANN approach, we analyzed 28 potential extraction and injection well locations that had been selected by hydrogeologists as capable of containing and cleaning up the groundwater contamination at Livermore within 50 years (Figure 7).

We were trying to identify the least expensive subset of these 28 locations that would prevent the spread of contaminants and remove as much as the full 28-location strategy. After using ANNs to evaluate 4 million of over 268 million possible subsets, we found acceptable strategies that involved as few as 8 to 13 locations and yet met containment and contaminant-removal goals. Installation, maintenance, and treatment costs associated with these strategies were less than $35 \%$ of those for the 28-location strategy. We now apply the ANN approach to well fields containing up to 268 potential locations and search for the optimal answers to a wide variety of management questions. 


\section{Modeling on the Internet}

To facilitate widespread access to our remediation data, the Laboratory's Environmental Restoration Division now has a home page on the World Wide Web that provides authorized users access to a wealth of accumulated data. Not only can users view and download static documents, images, and product and technology overviews, but they also have access to up-to-date project status information, statistical processing capabilities, database information, and estimating tools. At their desktop computer, they can view
HotMap, which provides a variety of information on any well or combination of wells at the Livermore site, or they can use PLANET, MapIt, or PDEase, a partial differential equation solver for inverse modeling (Figure 8). For the first time, Laboratory scientists and federal and state regulators have quick, timely access to data in a form that is useful to them.

\section{Looking Ahead}

Three-dimensional groundwater modeling is proving its usefulness on a regular basis, and it is still in its infancy.

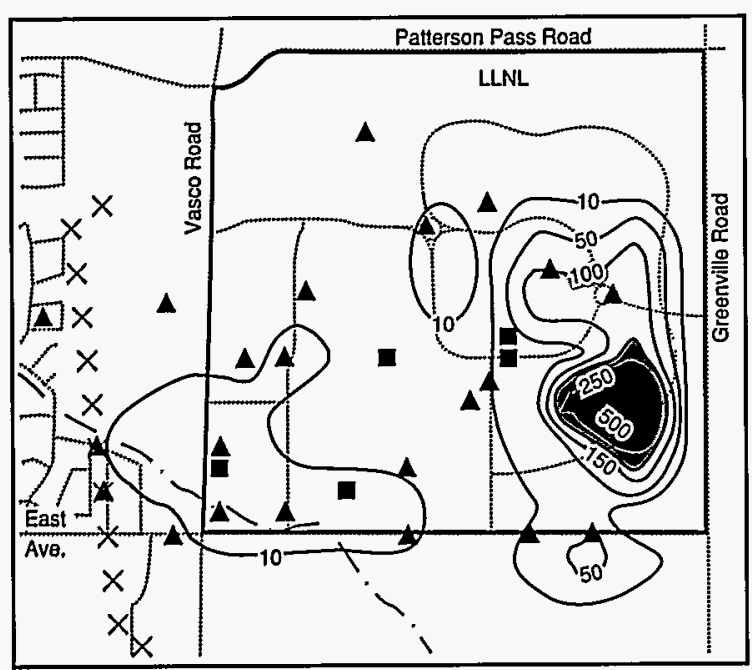

(a)

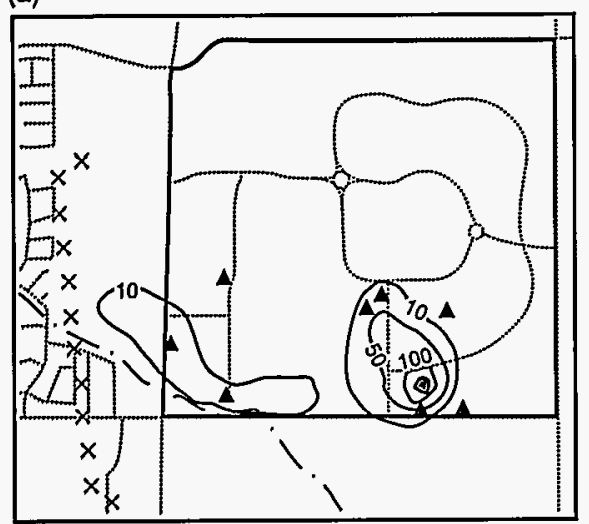

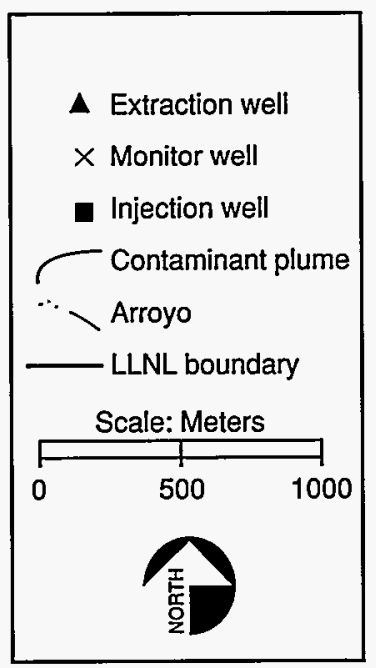

(b)

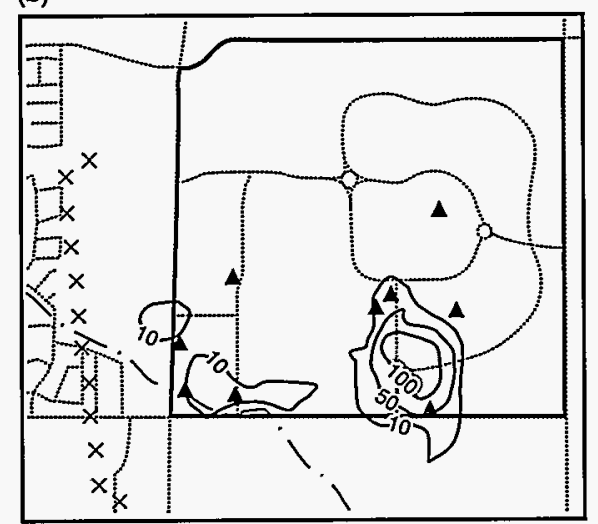

Figure 7. We use artificial neural networks (ANNs) and genetic algorithms to greatly accelerate the identification of optimal groundwater cleanup strategies. The larger figure represents the initial distribution of volatile organic compounds (VOCs) and the locations of 28 extraction and injection wells. The smaller three figures are the top-ranked patterns found after evaluating 4 million designs. The contours show VOC concentrations remaining after 50 years. Percentages in the table use the cost and performance of the full 28-well pattern as a point of reference. These evaluations are based on two-dimensional simulations of groundwater behavior.

\begin{tabular}{|r|c|c|c|}
\hline & (a) & (b) & (c) \\
\hline Number of locations & 8 & 9 & 13 \\
\hline Contaminant contained? & Yes & Yes & Yes \\
\hline $\begin{array}{r}\text { Percentage of } \\
\text { contaminant removed }\end{array}$ & $97 \%$ & $98 \%$ & $105 \%$ \\
\hline Cost relative to baseline & $26 \%$ & $31 \%$ & $34 \%$ \\
\hline
\end{tabular}

(c)

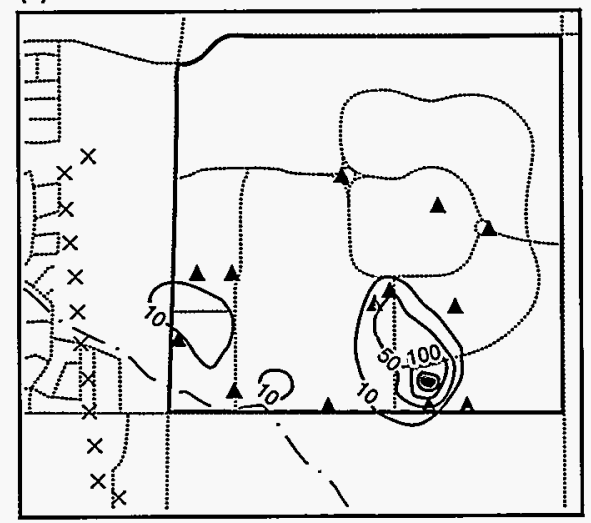


Advancing computer technology and our continued creativity are key to the further advancement of groundwater modeling at the Laboratory for beneficial use everywhere. It is interesting to note that the personal computers that can be

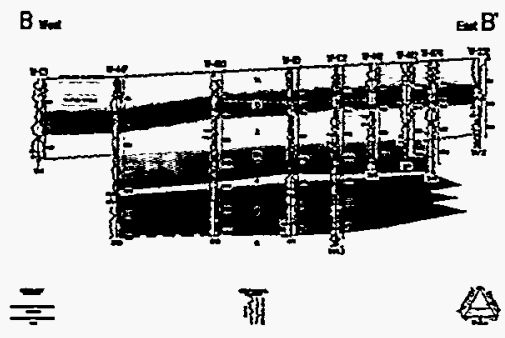

Figure 8. From the HotMap menu, an authorized user is linked to an array of information about the Livermore site. bought off the shelf today are as powerful as the Cray 1 supercomputers of less than 10 years ago. As computers become ever more powerful, our modeling capabilities can only expand for effective global applications.

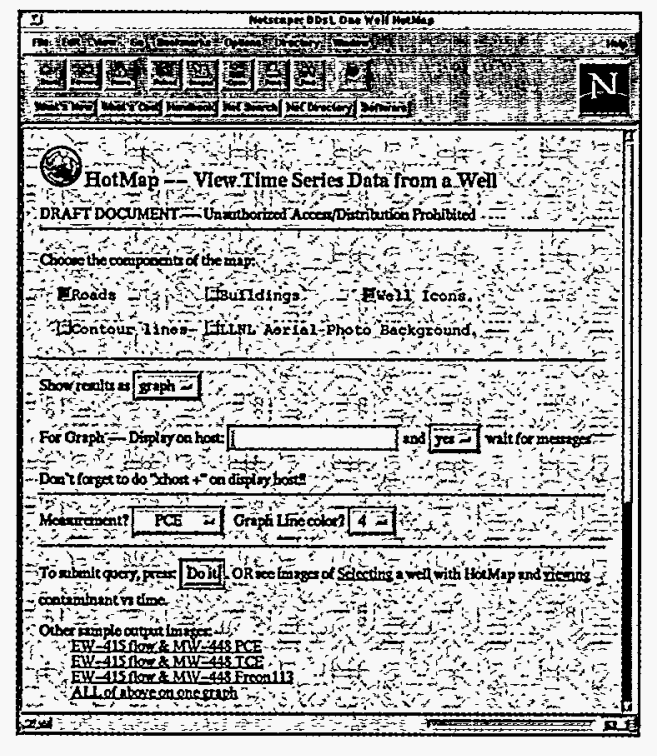

Key Words: artificial neural network (ANN), genetic algorithm, groundwater contamination, groundwater remediation, hydrostratigraphic analysis, inverse modeling, volatile organic compound (VOC).

References

1. "Groundwater Cleanup Using Hydrostratigraphic Analysis," Science \& Technology Review, UCRL-52000-961/2 (January/February 1996), pp. 6-15.

For further information contact Robert J. Gelinas (510) 423-2267 (gelinas1@IInl.gov). Information on flow and transport modeling is also available from Peter McKereghan of Weiss Associates (510) 450-6151. Virginia Johnson (510) 423-2005 (vmjohnson@IInl.gov) is a Laboratory expert on ANNs and genetic algorithm optimization.

\section{About the Scientist}

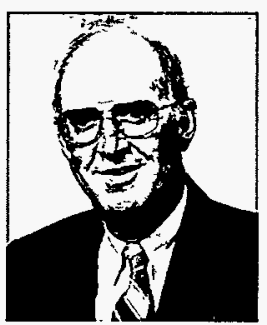

ROBERT J. GELINAS joined the Laboratory's Theoretical Physics Division in 1966 as an applied physicist. He received his Ph.D. (1965) and an M.S.E. (1961) in Nuclear Engineering and a B.S.E. (1960) in Chemical Engineering from the University of Michigan. He is currently the Environmental Transport Group Leader in the Environmental Restoration Division of the Environmental Protection Department. His experience includes leading groups of scientists and engineers in energy, defense, environmental, and high-power laser projects at both LLNL and in commercial R\&D, where he was principal scientist and manager of the Science Applications International Corporation facility in Pleasanton, California, from 1975 to 1985. Gelinas has published extensively in the fields of reactive fluid flow and transport, with applications to radiative weapons systems, atmospheric and subsurface environments, high-average-power and Nova-class lasers, hydrocarbons, nuclear systems, and nuclear weapons effects. 


\section{Dual-Band Infrared Tomography: S}

\section{Dual-band infrared computed tomography systems} developed at Lawrence Livermore are providing highly sensitive and accurate three-dimensional nondestructive inspection and evaluation of manmade structures in a variety of applications inside and outside the Laboratory.

\section{Computed}

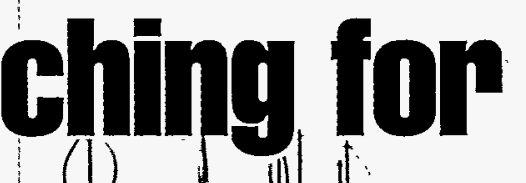

(1)
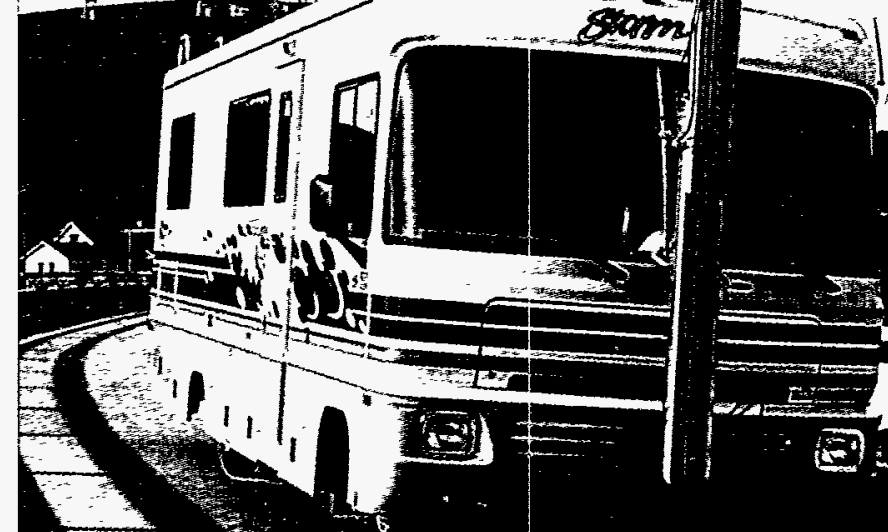

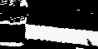
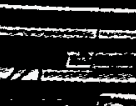
6

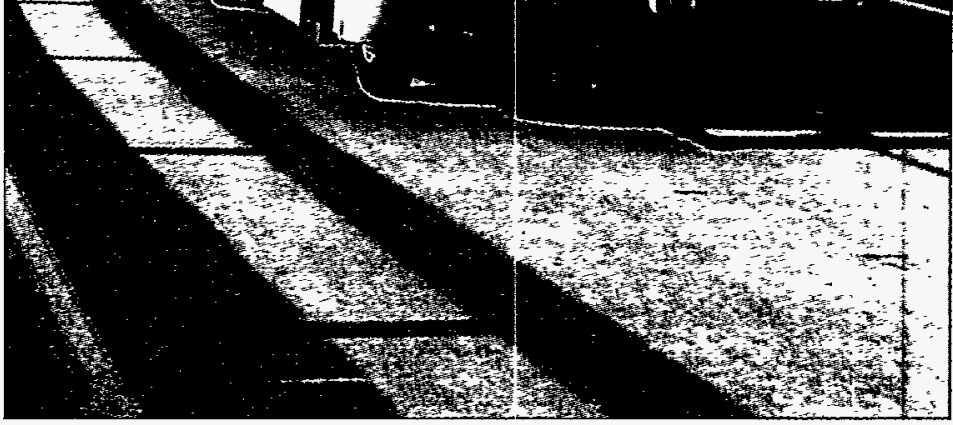

(Above) The dual-band infrared (DBIR) laboratory that the Federal Highway Administration is currently using for bridge inspection is a converted mobile home. The mobile DBIR laboratory's cameras, mounted about 4 meters ( $13 \mathrm{ft}$ ) above the roadway, scan the reinforced-concrete bridge deck for defects called delaminations. (Below) Delaminations are seen at the center of $(a)$ the 8- to 12-micrometer $(\mu \mathrm{m})$ longwave thermal infrared image and (b) the 3- to 5- $\mu \mathrm{m}$ shortwave image, both of which also show clutter. Clutter is identified in (c) the spectral difference map and later removed from (a) and (b) to create (d), which clearly shows only the delamination (minus clutter) as the bright yellow area with anomalous heat flow at the center of this image where temperatures are about $2^{\circ} \mathrm{C}$ warmer at noon and $0.4^{\circ} \mathrm{C}$ cooler at midnight.

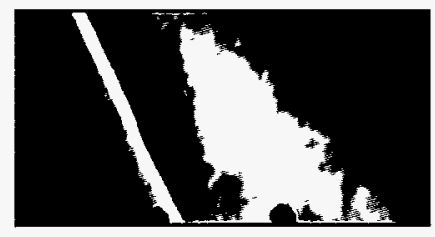

(a)

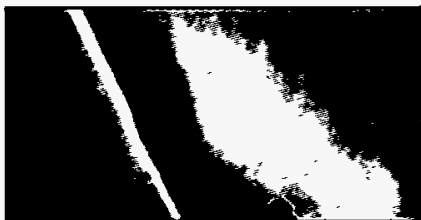

(b)

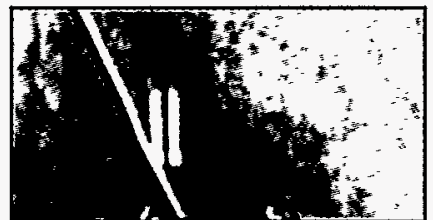

(c)

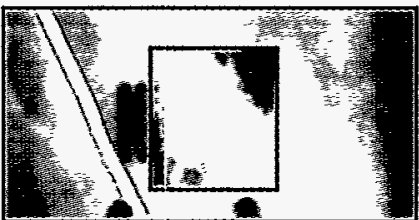

(d) 
Finding flaws in the bridges' concrete and asphalt roadbeds and repairing them is expensive-an estimated $\$ 3$ billion annually. In addition to the dollar outlay, there is the emotional cost: the aggravation that motorists endure while highway crews go about the slow, meticulous task of pinpointing problems. Currently, bridge crews must close lanes to traffic while they conduct visual inspections-looking for potholes, rust stains, cracks, or broken pavement. To detect hidden flaws, they manually drag a chain across the deck, listening for auditory differences that indicate areas of possible cracking-it is a little like rapping your knuckles along drywall, hunting for a secure anchor point. The chain technique, however, is slow, disruptive, unreliable, and costly and raises serious safety concerns. Also, it works only with concrete, not asphaltcovered roadways.

\section{Road-Testing the Technology}

The Laboratory's DBIR system provides reliable bridge inspections while minimizing lane closures. It is designed to eliminate the need to shut down lanes for routine inspections or have road crews risk possible injury as they dodge traffic. With the mobile unit, highway crews can conduct their examinations as they ride across a bridge. The Laboratory's system also will let inspectors peer beneath a roadbed's surface to hidden trouble spots before they get out of hand. For example, if defects like rebar corrosion are identified before they become serious, maintenance crews could perform less costly repairs.

\section{Delaminations (concrete layer} separations beneath the surface) can be discovered before they lead to possibly hazardous potholes. The FHWA team will test the prototype DBIR system this summer by using it to examine bridges and then compare the data collected with the defects road crews actually uncover and repair.

Steve Chase, the FHWA engineer in charge of nondestructive evaluation technology, calls the system, which was developed at the Laboratory, "an evolutionary development in bridge deck inspection." While traditional infrared imaging systems work at only one wavelength, the Laboratory's system collects images at two separate ranges of wavelengths ( 3 to 5 and 8 to 12 micrometers), allowing greater precision in computer calculations of temperatures. The dual-band system compensates for the influence of surface contamination on materials and surface compositional differences, both of which can skew readings in traditional, single-band systems.

The bridge inspection DBIR system taps into the Laboratory's well-honed expertise in nondestructive inspection and evaluation, developed over the years in support of the nation's nuclear weapons program. The system also capitalizes on ideas proposed by the Laboratory for detection of buried land mines during the Gulf War.

In fiscal year 1994, the Laboratory began adapting the DBIR technology to meet the Federal Highway

Administration's needs. Feasibility tests were conducted with tower-mounted infrared cameras, which overlooked asphalt-covered and exposed concrete slabs that served as a surrogate bridge deck. (See the illustrations in the box on p. 25.)

The feasibility tests were used to optimize the DBIR system response to thermal differences between normal and defective concrete structures and to clarify interpretation of corrosion in steel reinforcements that causes hidden delaminations. These hidden flaws are typically masked by clutter from oil, grease, paint, patches, shadows, rocks, wood, plastic, metal, or concrete composition variations.

With good results from the feasibility study, the Livermore team last year mounted DBIR cameras on a telescoping mast located at the front of a motor home that had been converted for field tests. The mobile DBIR Bridge Deck Laboratory successfully completed its first road test in November 1995 on the Grass Valley Creek Bridge near the Northern California town of Weaverville. Scientists were able to view 1-meter-long sections of roadbed approximately 1 meter ( $3 \mathrm{ft}$ ) long and one lane ( 3 meters or $10 \mathrm{ft}$ ) wide while traveling at 40 kilometers per hour ( $25 \mathrm{mph}$ ). VIEW computer codes developed at Livermore sped processing and analysis of the images, which had been recorded and stored on a high-speed hard disk.

Livermore researchers are awaiting results of the spring and summer 1996 shakedown tests by the Highway Administration before planning the next phase of their DBIR activities. The FHWA's Chase is optimistic about the technology's future: "If it proves to be a valuable technology, and I think it will," he says, "there's potential for commercialization by a private company."

\section{Aging Aircraft Applications}

According to the Laboratory's Nancy Del Grande, a principal scientist for DBIR inspection capabilities development, the technology has numerous applications in addition to FHWA bridge inspections. The technology has applications in Laboratory programs-identifying thermal stress and damage to optical components used for the National Ignition Facility, measuring emissivity and radiative heat transfer for Stockpile Surveillance, and characterizing the thermal efficiency of the uranium 


\section{Dual-Band Infrared Computed Tomography: How It Works}

The use of dual-band infrared computed tomography (DBIRCT) imaging as an inspection tool is based on the knowledge that flawed and corroded areas of a manmade material or structure heat and cool differently than do areas with no defects. DBIR-CT uses two thermal infrared bands to provide time sequences of high-contrast images called temperature maps of naturally or flash-heated materials and structures. When these maps are processed using computer codes developed at LLNL, they unfold the location and amount of hidden defect and corrosion damage. DBIR-CT enables researchers to analyze heat flow patterns at 10 times the sensitivity of single-band systems, to image structural defects in three dimensions, to differentiate surface and subsurface clutter from corrosion damage, and to quantify that damage so that major damage in need of immediate attention can be differentiated from minor defects.

The DBIR inspection and evaluation process works like this (see the figure below): First the material or structure is heated either naturally by the sun or artificially using pulsed lasers, quartz lamps, or flash lamps. Bridge decks, for example, are naturally heated; airplane fuselages are heated by flash lamps. The material or structure is scanned by the DBIR-CT system. using two ranges of infrared wavelengths -3 to 5 and 8 to 12 micrometers. The resulting time-sequence temperature maps
(Figures $\mathrm{c}-1$ and $\mathrm{c}-2$ below) at each wavelength show heat-flow anomalies that could be caused by defects or corrosion or by clutter such as paint or junk metal on the road surface (in our example below) or subsurface globs of excess epoxy within an airplane skin.

To weed out clutter, the temperature maps are processed using the computed tomography capabilities provided by the VIEW computer code developed at LLNL. The resulting DBIR imageratio patterns on the temperature map (Figure c-3) showing temperature variations from both surface-only features and from subsurface defects are compared to DBIR image-ratio patterns related to "emissivity noise" (Figure $c-4$ ) that show only surface clutter. The clutter from unseen concrete chemical differences stands out clearly on the emissivity-noise map, and when the emissivity-noise patterns are subtracted from the temperature map that shows both emissivity noise and defects, the resulting temperature map (Figure $\mathrm{c}-5$ ) shows only the flaw's-their location, size, shape, depth, and severity.

The DBIR system's capabilities shown in the results of laboratory tests (see the figures below) have been confirmed by field tests (see the images bottom of p. 23) and are being put to use in further highway tests by the Federal Highway Administration that began in April 1996.

(a) 1.8-m (6-ft) square concrete test slab $18.4 \mathrm{~cm}(7.5$ in.) thick with

(b) five surface clutter sites (A-E) along the perimeter and five

Styrofoam delamination sites $(i-5) 5.1 \mathrm{~cm}$ below the surface.
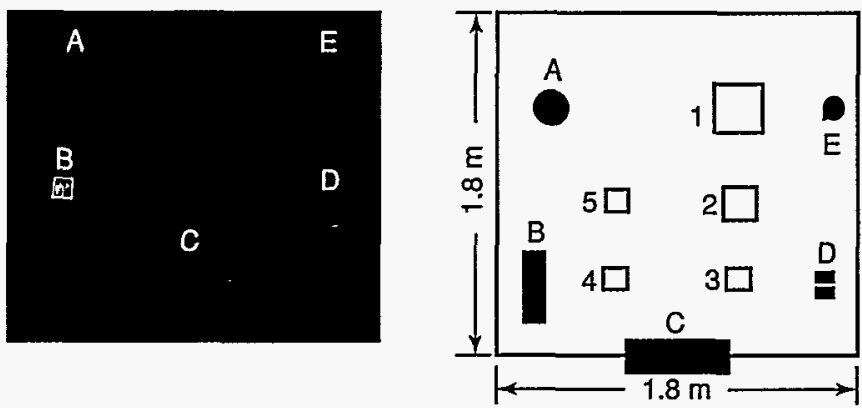

(c-1) 8- to 12- $\mu \mathrm{m}$ longwavelength temperature map.

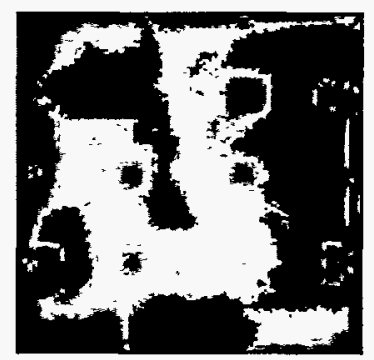

(c-2) 3- to 5- $\mu \mathrm{m}$ shortwavelength temperature map.

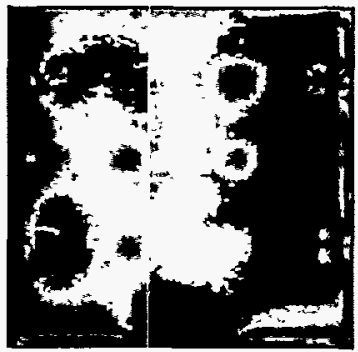

$(0-3)$ Temperature map showing surface clutter and subsurface defects.

(o-4) Emissivity-noise map showing surface clutter only.
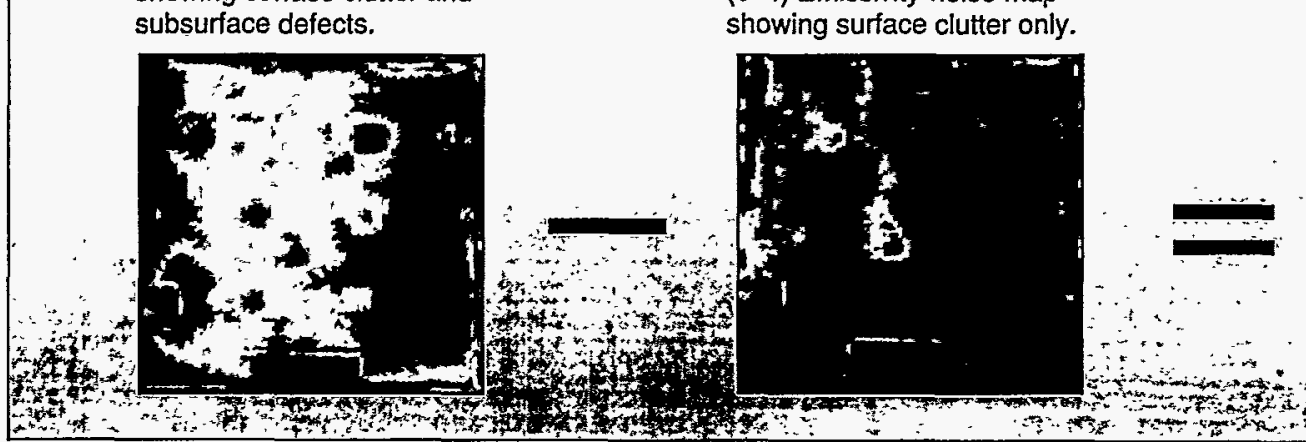

(o-5) Temperature map showing subsurface defects only.

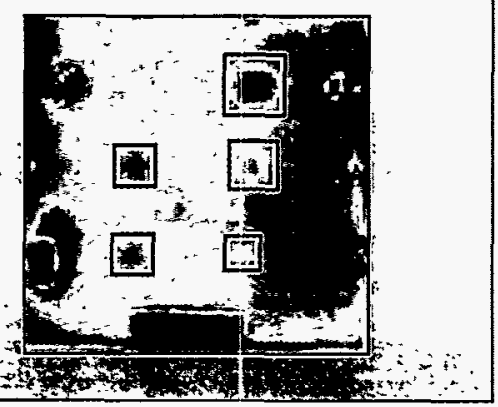


Figure 1. (a) Phil Durbin uses the DBIR system scanner, flashlamp, and spectral hood to look for metal loss from corrosion within the skin of an airplane. (b) What the DBIR system sees over time after flashlamp heating. Early- and latetime thermal inertia, temperature, and cooling-rate maps distinguish, through the power of computed tomography, subsurface clutter (shallow sealant excess) from deep corrosion (metal loss) in lapped metal splices.

spin-forming process for our Advanced Development and Production Technology. Applications in areas outside Lawrence Livermore programs include detecting corrosive thinning and pitting within exposed petrochemical pipelines, assessing structural damage in reinforced concrete buildings, and analyzing the steel wall thickness and integrity of radioactive waste containers. Since early 1992, Del Grande and her associates have developed DBIR to quantify metal corrosion in aircraft fuselages, with funding from the Federal Aviation Administration's Technical Center.

Currently, aircraft inspectors use visual, ultrasound, and electronic

(a)

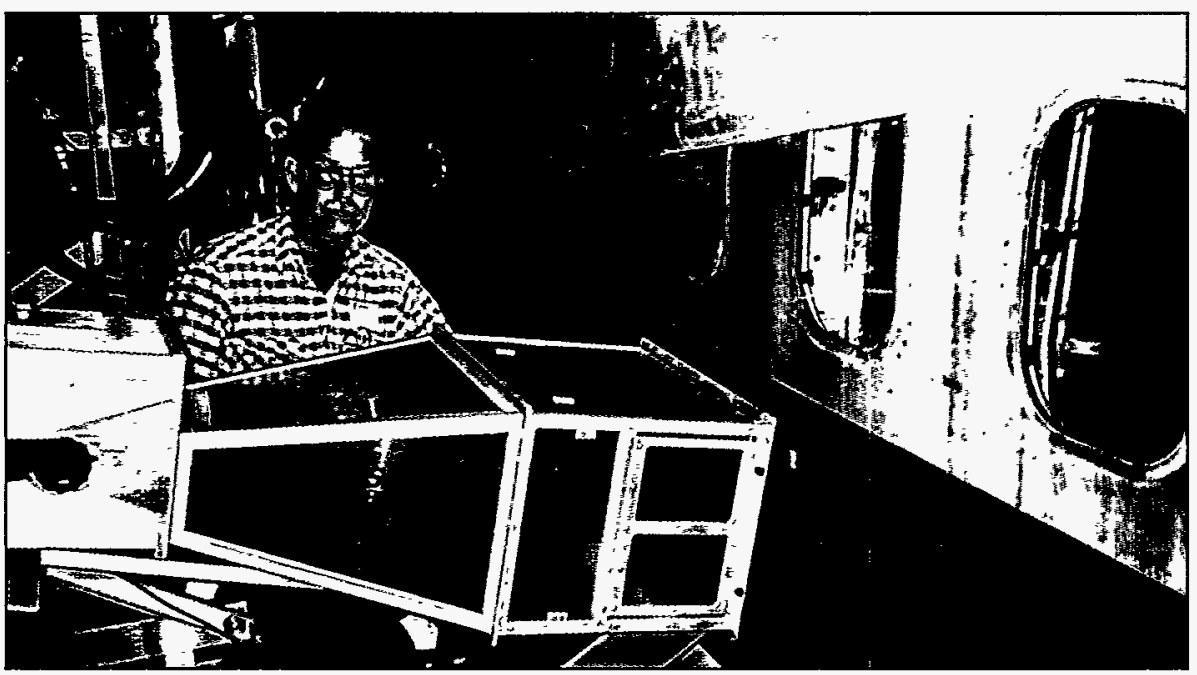

(b)

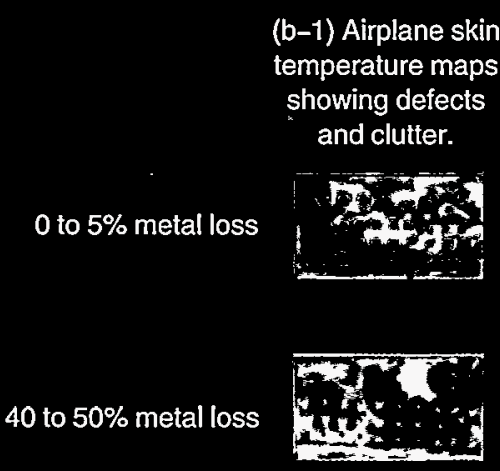

(b-2) Timegram cooling-rate maps of defects and clutter.

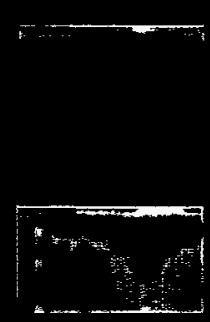

Shallow sealant excess (b-3) Early-time thermal inertia maps showing shallow clutter in red.

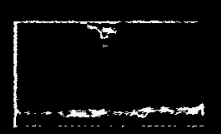

(b-4) Later-time thermal inertial maps showing deep defects in red.
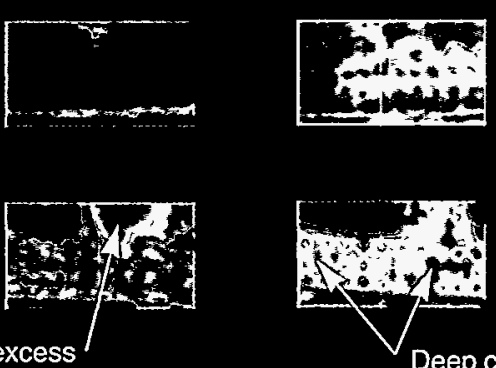

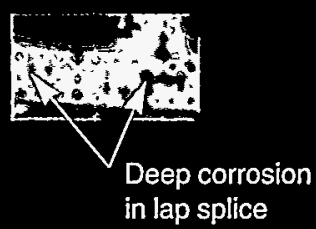

Temperature maps (left to right) compare ( $b-1)$ airplane skin temperatures at two locations, (b-2) timegram cooling rates at those same locations, (b-3) early-time thermal inertias ( 0.1 to 0.5 seconds) after flash heating at the locations, and (b-4) late-time thermal inertias ( 1 to 3 seconds after heating) for (top row) noncorroded or barely corroded (0 to $5 \%$ melal loss) aircrait skins and (bottom row) heavily corroded ( 40 to $50 \%$ metal loss). 
techniques to look for fuselage defects. However, in order to determine the extent of corrosion damage, the fuselage must be taken apart.

Livermore's DBIR detection methods do not require aircraft disassembly. When applied to aircraft studies, DBIR can show the extent of metal corrosion near the aircraft skin's surface or deep within it. (Figure 1.) It can characterize the type of defects involved-such as gaps or areas with poor adhesive bonds with or without metal loss from corrosion. Also, it can differentiate between corrosion and conditions that may be mistaken for corrosion, such as fabrication ripples, surface roughness, and uneven sealant in a lap joint.

While the DBIR system for bridge inspections relies on natural heat sources, the system for aircraft inspections uses flashlamps and thus relies more on the computed tomography (CT) aspects of the technology than do DBIR bridge inspections. The metal skin is heated with uniform thermal pulses each lasting a few milliseconds. The resulting surface temperature changes, which vary with location and time, are then imaged by the dual-band scanner for analysis by computer. Hotter readings indicate areas of potential corrosion. A patent on the Laboratory's active (flash-heated) and passive (diurnally-heated) DBIR processes for imaging anomalous structural heat flows was issued in August 1995.

Livermore researchers have conducted several DBIR-CT tests on commercial aircraft. A demonstration at Boeing in early 1995 used a uniform pulsed-heat source to stimulate infrared images of hidden defects in an aircraft fuselage. The DBIR camera and image processing system produced temperature, thermal inertia, and cooling-rate maps. In combination, these maps characterized the defect site, size, depth, thickness, and type. LLNL researchers are able to quantify the percent metal loss from corrosion above a threshold of $5 \%$, with overall uncertainties of $3 \%$.

The Laboratory team's goal is to produce a single corrosion defect map that eliminates clutter from excess sealants, ripples, and surface features. Such a map could be incorporated in a commercial DBIR scanner, making it easier to assess damage. The Laboratory has worked out a Cooperative Research and Development Agreement with Bales Scientific Incorporated to commercialize DBIR corrosion inspection technology.

A recent round-robin investigation of nondestructive investigation equipment used to detect hidden corrosion on U.S.
Air Force aircraft indicated that false detection of corrosion results in costly, unnecessary, and destructive exploratory maintenance, said Del Grande. "We expect our technology to cut the cost of destructive exploratory maintenance in half by eliminating clutter," she said.

Key Words: dual-band infrared computed tomography, nondestructive inspection and evaluation.

\section{For further information contact Nancy Del Grande (510) 422-1010 (delgrande1@llnl.gov). Other key Laboratory researchers on the DBIR projects are Phil Durbin, Project Manager, Federal Highway Administration project (510) 422-7940 (durbin2@IInl.gov) and Ken Dolan, project manager, Federal Aviation Administration project} (510) 422-7971 (dolan2@IInl.gov).

\section{About the Scientist}

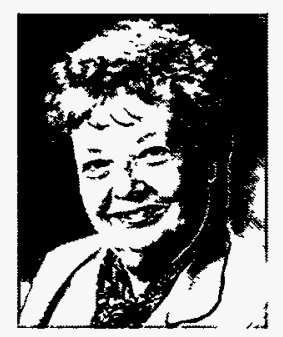

NANCY DEL GRANDE (née Kerr) received her A.B. in physics from Mount Holyoke College in 1955 and her M.S. in physics from Stanford University in 1957. She joined the Laboratory's Test Program in 1959. She became the first woman to design and conduct an experiment using $\mathrm{x}$-ray spectroscopy to measure the temperatures of nuclear devices stored underground at the Nevada Test Site. She pioneered the technology transfer of $\mathrm{x}$-ray band infrared (DBIR) precise airborne temperature measurement method for detecting underground objects and applied it to depict deep aquifers at the Long Valley, California, geothermal resource area and to locate buried land mines at the Yuma Proving Grounds.

In 1992, she transferred to the Nondestructive Evaluation Section of the Laboratory's Engineering Sciences Division where she has been principal investigator and principal scientist for DBIR imaging projects to detect corrosion in aging aircraft (1992-1995) and delaminations in bridge decks (1993-present). She is the author or co-author of over 50 publications on $\mathrm{x}$-ray spectroscopy and infrared physics and has been issued two patents, one for a technology to identify anomalous terrestrial heat flows from buried and obscured objects, and another a system to image anomalous structural heat flows from corrosion within aircraft skins and bridge decks. 


\section{Plating Shop Moves to Finish Off Waste}

W HEN physicists at Stanford Linear Accelerator Center's

"B-factory" last year needed to coat two dozen 35.6-cm tall cavities with pure copper and ultraclean some 50,000 other parts for a set of unprecedented high-energy experiments, they turned to specialists at the Lawrence Livermore Chemical and Electrochemical Processes Facility.

The facility is operated by the Metal Finishing Group of Mechanical Engineering's Manufacturing and Materials Engineering Division. Over the past three decades, the facility has earned a reputation as one of the top-flight metal finishing centers in the nation, using chemical and electrochemical processes for wide-ranging assignments from LLNL research programs, other national laboratories, and international research agencies such as CERN (the European high-energy physics research organization).

During the past few years, the facility has also made a name for itself by embracing environmentally conscious manufacturing principles. Working in stages, the shop has adopted scores of improvements that included recycling strong acids, substituting Earth-friendlier materials, and eliminating cyanide in its operations. The advances have been made as part of a larger, Laboratory-wide effort to encourage pollution prevention and waste minimization activities.

The operation's environmental efforts have been so successful that the facility has decreased its discharge of water to the Livermore sewer system from 11.4 million liters (3 million gallons) to zero! And whereas in 1991 the facility was producing 227,100 liters $(60,000$ gallons) of chemical waste to be trucked off site, it now'produces only 3,785 liters (1,000 gallons) of this waste annually, a dramatic reduction.

As a result of these accomplishments, plating shop personnel are sharing lessons learned with both Department of Energy centers and private firms on how to respond to tightened environmental regulations and waste disposal costs by minimizing wastes and substituting better procedures.

The products of chemical and electrochemical finishing are found throughout modern society, from galvanized nails to shiny chrome-plated faucets, from automobile trim to the gold and silver electrical contacts in computers and telephones. Such finished parts can be stripped and replated if they tarnish, scratch, or wear out. However, heavy metals, toxic chemicals, and large volumes of waste (much of it hazardous) for many years seemed an inescapable part of the metal finishing business at the Laboratory and elsewhere.
One of the two dozen

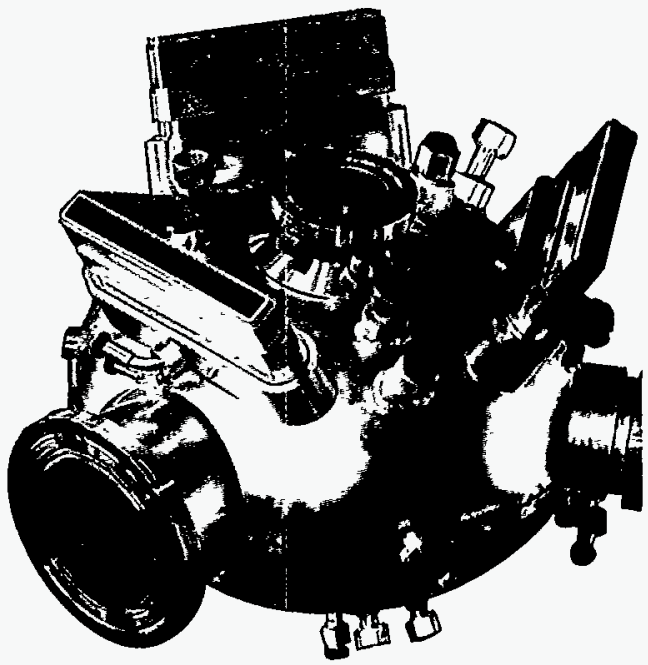

radiofrequency cavities

coated with copper by the Laboratory's Chemical and

Electrochemical Processes Facility as part of our work on the

Stanford Linear Accelerator Center's "B-factory." The cavities

are $60 \mathrm{~cm}$ in diameter and $35.6 \mathrm{~cm}$ tall.

But that assumption changed for Livermore in the late 1980s, according to Jack Dini, Materials Engineering and Mechanics section leader, when the Chemical and Electrochemical Processes Facility began to scrutinize its operations with an eye on minimizing waste and preventing pollution. The in-depth look was prompted by stiffer regulations, higher costs to dispose of wastes, a growing environmental consciousness, and the appearance of new techniques in the marketplace that used fewer hazardous materials and produced less hazardous wastes. The result was modification of many operations over several years, but most importantly, says Dini, the adoption of a different mindset centered on incorporating environmental consciousness in every facet of the facility's operations.

"Today we have a safer and cleaner facility, produce much less pollution, and have maintained the quality of parts processed through our operation," Dini says. "Being in the forefront of both metal finishing technology and waste minimization is not only possible, but they go hand in hand."

What's more, the environmental changes have produced sizable cost savings. Today the facility is saving more than $\$ 500,000$ per year. According to Chris Steffani, shop supervisor, many of the savings resulted from relatively simple material substitutions. For example, costly chlorinated cleaning compounds were replaced with much cheaper, and more environmentally kind, materials. For more thorough cleaning, high frequency sound waves remove very fine particulates, and the residual water is recycled for another round of cleaning chores.

Because wastewater typically represents the largest waste stream, shop personnel have given it very high priority. 
Material discharged to municipal sewers must meet strict guidelines, and wastes that must be trucked off site cost at least 75 $\phi$ per liter ( $\$ 3$ per gallon) for transport, treatment, and disposal. Standard degreasing equipment was replaced with a variety of aqueous cleaning processes including soak and electrolytic cleaning and ultrasonic cleaning (mentioned above). These were connected to a rinse water recycling system capable of recycling 2,840 liters ( 750 gallons) a day. The recycled water is further purified by an ion exchange unit for operations other than simple rinsing.

As a result of these actions, the facility is saving over 11.4 million liters ( 3 million gallons) of water per year and no longer sends any water to the City of Livermore's sewer system. What's more, the shop's recycled water has fewer metallic ions than the water supplied to city residents. Nominated by the City of Livermore, the Laboratory received a 1993 award in recognition of these accomplishments from the California Water Pollution Control Association.

\section{Dealing with Acids}

Minimizing the use and waste of inorganic acids has been one of the facility's largest concerns. Such acids are commonly used in shops to remove surface blemishes, produce bright surfaces, strip unwanted metals and coatings, and prepare metal surfaces to receive other coatings. The acids are also used as electrolytes for coatings produced by electrolytic oxidation such as anodizing. Eventually the acids become unusable or weakened because of contamination with metals or the conversion of hydrogen ions into hydrogen gas. The acid then becomes waste and a new acid batch is started.

The facility installed diffusion dialysis equipment to recover acids and separate the metal component for recovery and sale to refineries. The equipment uses a new kind of membrane that can withstand low $\mathrm{pH}$ solutions. Using this system, the facility now recycles spent solutions of nitric, sulfuric, and hydrochloric acids with a recovery efficiency of about $80 \%$.

In addition, the facility is now using ferric sulfate material to clean aluminum parts as a substitute for a process that used concentrated acids. The new solution lasts much longer and does not cause a problematic insoluble aluminum fluoride film that formed with the acid process.

Also, the facility substituted oxalic acid for sulfuric acid when anodizing aluminum. Because oxalic formation is much less corrosive than sulfuric acid, equipment, floors, and tanks last much longer. As an added bonus, anodized aluminum coatings with oxalic acid are much smoother.

Another approach to minimize waste has been to extend the life of materials. A case in point is electroless nickel solutions, widely used to coat a variety of surfaces by immersion in a bath containing a chemical reducing agent. The solutions have a tendency to spontaneously plate out on the tank and associated equipment, adding to the plating cost. Also, expensive treatment is required before the spent solution can be disposed of. In response, Steffani and his technicians incorporated an electrodialysis process that reduces both chemical purchases and disposal costs. The technology separates dissolved solids from the nickel ions, making it possible to reuse the tanks many times without disposal. The electrodialysis operation is simple and runs virtually unattended.

\section{Substituting New Technologies}

One of the most important materials substitutions was made for hexavalent chromium plating, until recently the standard chromium plating process. This process generates air emissions, effluent rinse water, and solutions that are toxic and suspected of being carcinogens. Facility people estimated that it would cost about $\$ 25,000$ to demonstrate compliance with
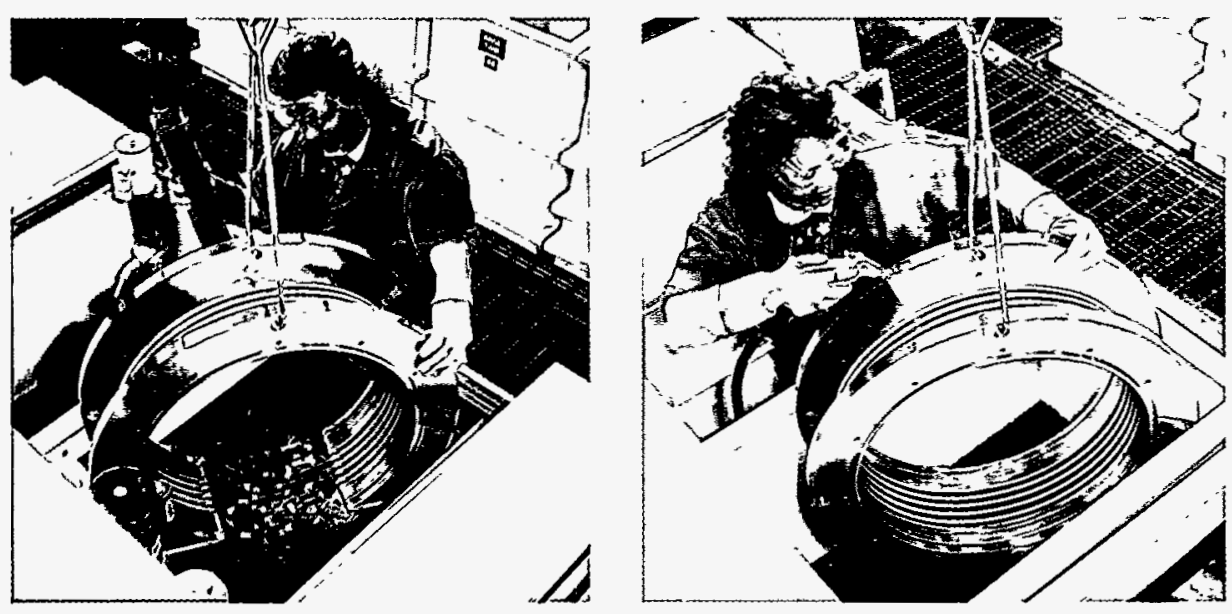

Kelye Allen of Livermore's plating shop plates (left) a metal bellows component to be used in the Laboratory's lasers program with an environmentally friendly nickel-tungsten-boron deposit, which replaces hexavalent chromium, a plating material that is a source of toxic and possibly carcinogenic air and water pollutants. On the right, she rinses off excess nickel-tungsten-boron material with water that is treated and reused. 
tougher Bay Area Air Quality Management District regulations on emissions from hexavalent chromium and that compliance costs would mount in future years.

As a result, the facility adopted a compound composed of $59.5 \%$ nickel, $39.5 \%$ tungsten, and $1 \%$ boron as a substitute for hexavalent chromium. The new material has excellent wear, corrosion resistance, and mechanical properties. It also poses less of an environmental risk and reduces energy costs.(See the photos on p. 29.)

Much of the effort to adopt more environmentally friendly procedures and materials has centered on cyanide. Because of the hazardous nature of cyanide, extensive safety precautions must be incorporated when manufacturing the electroplating chemicals, transporting them to user sites, using the electroplating process, and disposing of wastes. For example, if cyanide-based solutions become too acidic, large amounts of poisonous cyanide gas are liberated. The electroplating industry as a whole has suffered many accidents - and a few deaths-from cyanide use. In addition, cyanide use costs more-disposal costs for LLNL wastes containing cyanides are about $\$ 1.50$ per liter ( $\$ 6$ per gallon) compared to $75 \notin$ per liter (\$3 per gallon) for noncyanide wastes.

Over the past several years, the Livermore facility found substitutes for almost every process involving cyanide. For example, copper cyanide plating was replaced with a copper pyrophosphate process. The substitution works quite well and produces parts as good as those obtained with the copper cyanide process.

Until recently, silver was the remaining metal still relying on cyanide formulations for electrodeposition of lasting and relatively thick deposits. In fact, silver-cyanide plating solutions are the most highly concentrated cyanide solutions used in the plating industry.

In the spring of 1995, LLNL entered into a \$2-million Cooperative Research and Development Agreement (CRADA) with Technic Inc. of Providence, Rhode Island, with the goal of providing industry with an environmentally benign alternative to the silver-cyanide plating process for depositing thicknesses greater than 250 micrometers. Laboratory researchers have obtained stress and hardness data and have analyzed the structure of the deposit with metallography and $\mathrm{x}$-ray diffraction. The results show that the electroplating industry for the first time can confidently plate silver with a process that uses no cyanide.

The CRADA effort has been so successful that the Laboratory has nominated our partner for a President's Green Chemistry Challenge Award, a program sponsored by a voluntary partnership of industry, the American Chemical Society, the Council for Chemical Research, and the U.S.
Environmental Protection Agency. This awards program recognizes fundamental breakthroughs in chemistry that are useful to industry and accomplish pollution prevention through source reduction.

\section{Helping Small Firms}

Another successful collaboration is with the Northern California Association of Metal Finishers. This partnership, sponsored by the LLNL's Small Business Initiative, established a Model Metal Finishing Facility at the Laboratory's Chemical and Electrochemical Processes Shop to assist regional businesses in acquiring and implementing chemical processing technology and providing waste minimization consultation.

Steffani handles calls daily from small metal finishers with questions on minimizing waste or about technical processes. Many calls result in immediate solutions. Other calls involve a request to tour the Laboratory facility or to use the model facility for a few days to work on a new process. Steffani has toured more than 70 small electroplating facilities and helped many of them set up waste minimization programs of their own.

A new partnership is with the U.S. Environmental Protection Agency's Common Sense Initiatives, a program aimed at enhancing interaction between business and the EPA. In a $\$ 300,000$ project supported jointly by EPA and LLNL's Small Business Office, the Chemical and Electrochemical Processes Shop is selecting four to five projects aimed at helping small electroplating businesses establish waste minimization and pollution prevention programs. Dini notes that a third of the nation's small electroplating firms have gone out of business in recent years largely because of the burden of meeting environmental regulations.

To date, the shop's largest partnership is with Stanford Linear Accelerator Center (SLAC), Lawrence Berkeley National Laboratory, and other LLNL programs to design and build the so-called "B-factory" (named after the elusive B-meson subatomic particle) at SLAC. (See the photo on p. 28.) The shop is receiving $\$ 750,000$ for ultracleaning some 50,000 parts that make up 1,400 ion pumps and for copper coating 300 meters of connecting pipe and two dozen, $60-\mathrm{cm}-$ diameter, 35.6-cm-tall radio-frequency cavities that will keep electrons traveling at nearly the speed of light.

Key Words: metal finishing-chemical and electrochemical processes, electroplating; pollution prevention; waste minimization.

\footnotetext{
For further information contact Jack Dini (510) 422-8342 (dini1@IInl.gov) or Chris Steffani (510) 423-1780 (steffani1@IInl.gov).
} 

our employees as well as to indicate the scale and scope of the work

done at the Laboratory.

\begin{tabular}{lll} 
Patent issued to & Patent title, number, and date of issue & Summary of disclosure \\
\hline $\begin{array}{l}\text { Daniel D. Dietrich } \\
\text { Robert F. Keville }\end{array}$ & $\begin{array}{l}\text { Electron Source for a Mini lon Trap } \\
\text { Mass Spectrometer }\end{array}$ & $\begin{array}{l}\text { An integrated electron source and mass analyzer/detector with miniature } \\
\text { ion cyclotron resonance mass spectrometer (MS) having low power } \\
\text { consumption and ion trap MS that Fourier analyzes the ion cyclotron } \\
\text { resonance signals induced in the trap electrodes. This portable, low- } \\
\text { power MS with integrated sensors and electronics can detect } \\
\text { environmental pollutants and illicit substances. }\end{array}$ \\
\hline December 19,1995 & $\begin{array}{l}\text { High Speed Sampler and } \\
\text { Demultiplexer }\end{array}$ & $\begin{array}{l}\text { A demultiplexer based on a plurality of banks of samplers (each bank } \\
\text { comprising transmission lines for transmitting an input signal) and strobe } \\
\text { signal and sampling gates at respective positions for sampling the input } \\
\text { signal in response to the strobe signal. Strobe control circuitry is coupled } \\
\text { to the plurality of banks and supplies a sequence of bank strobe signals } \\
\text { to the strobe transmission lines. }\end{array}$ \\
\hline
\end{tabular}

\begin{tabular}{lll}
\hline $\begin{array}{l}\text { Ger Van den Engh } \\
\text { Richard J. Esposito }\end{array}$ & Multiple Sort Flow Cytometer & $\begin{array}{l}\text { A flow cytometer with means for deflecting and focusing charged droplets } \\
\text { into multiple streams. A pair of oppositely charged plates disposed on } \\
\text { each side of a droplet flow with a respective ground plane for each plate } \\
\text { produce a curved and focused electric field between the plates to more } \\
\text { accurately focus deflections of the charged droplets. }\end{array}$ \\
\hline
\end{tabular}

Robert J. Contolini Steven T. Mayer

Lisa A. Tarte
Removal of Field and Embedded Metal by Spin Spray Etching

U.S. Patent $5,486,234$

January 23, 1996

Troy W. Barbee, Jr. Gary W. Johnson

Dennis W. O'Brien

High Performance Capacitors Using Nano-Structure Multilayer Materials Fabrication
U.S. Patent $5,486,277$ January 23,1996

Margaret L. Carman Kenneth J. Jackson Richard B. Knapp John P. Knezovich Nilesh N. Shah

Robert T. Taylor

\section{Methods for Microbial Filtration of Fluids}

U.S. Patent $5,487,834$

January 30,1996
A process for uniformly removing metal from a substrate surface and above metal-containing trenches formed in the substrate for producing an essentially planar surface across the substrate and the trenches. The surface is rotated while directing an etchant onto the surface.
Silicon on Insulator with Active Buried Regions

U.S. Patent $5,488,012$

January 30,1996
The fabrication of high energy-density capacitors by nano-engineered, multilayer synthesis technologies, whereby the materials, thickness of layers, interfacial quality, and conductor configuration can be precisely controlled. Magnetron sputtering of very thin conductive and dielectric layers is used.
A method for purifying contaminated subsurface groundwater by contacting the contaminated subsurface groundwater with resting state methanotrophic or heterotrophic microorganisms that produce long lifetime contaminant-degrading enzymes. The micro-organisms are derived from surface cultures and are injected into the ground to act as a biofilter. The contaminants include organic or metallic materials and radionuclides.
A method for introducing patterned buried components in a silicon layer and forming contacts for the buried components in the thin silicon layer after fabrication of the silicon-on-insulator (SOI). This process can be accomplished by using excimer laser-doping techniques during the formation of the SOl and after the SOI has been fabricated. This method applies to SOI wafers made from a silicon wafer bonded to a substrate such as glass or an oxidized silicon wafer. 


\section{Mitigating Lightning Hazards}

A new draft document provides guidance for assessing and mitigating the effects of lightning hazards on a Department of Energy (or any other) facility. Written by two Lawrence Livermore engineers, the document combines lightning hazard identification and facility categorization with a new concept, the Lightning Safety System, to help dispel the confusion and mystery surrounding lightning and its effects. The guidance is of particular interest to DOE facilities storing or handling nuclear and high-explosive materials. The concepts presented in the document were used to evaluate the lightning protection systems of the Device Assembly Facility at the Nevada Test Site.

Contact:

Richard Hasbrouck (510) 422-1256 (hasbrouck1 @IInl.gov).

\section{Groundwater Modeling: More Cost- Effective Cleanup by Design}

Mathematical modeling allows groundwater remediation planners at Lawrence Livermore National Laboratory to view the soils and pathways in the site's subsurface where contaminated groundwater moves. To improve our picture of the subsurface, we have developed innovative approaches to groundwater modeling and a number of programs that facilitate our use of industry-standard simulation codes. We are applying artificial neural network (ANN) technology to evaluate and optimize "smart" pump-and-treat remediation. We have developed PLANET, a graphical user interface for rapid evaluation of pump-and-treat scenarios, and MapIt, a software tool that can read almost any type of data source and quickly produce input files for a host of simulation codes. Evaluation and data input tasks that used to take weeks and months have been reduced to hours, minutes, or even seconds. These tools and technologies can be used by remediation planners at any site in need of groundwater cleanup. The ability to forecast a groundwater remediation project to its closure allows planners to reliably reduce time and cost as the project progresses.

Contact:

Robert J. Gelinas (510) 423-2267 (gelinas1@IInl.gov).

\section{Dual-Band Infrared Computed Tomography: Searching for Hidden Defects}

Federal highway officials estimate that $20 \%$ of the country's half-million two-lane bridges are structurally deficient. In April 1996, the Federal Highway Administration began road testing a dual-band infrared computed tomography (DBIRCT) system developed at Lawrence Livermore that images in three dimensions the defects in the subsurface of bridge decks by using two thermal infrared bands to sense time-dependent temperature differences. Mounted on a converted motor home, the system can scan a 3-meter-wide (10-ft) lane on a bridge and locate defects while traveling at $40 \mathrm{~km} / \mathrm{h}$ $(25 \mathrm{mph})$. This system enables inspectors to peer beneath a roadbed's surface to find and evaluate hidden trouble spots before they become hazardous. In addition to its applications for the nondestructive inspection and evaluation of bridge decks, DBIR-CT has a number of other applications both inside and outside the Laboratory. Recently, for example, it has been used to detect corrosion within the skins of aircraft and differentiate it from other benign subsurface anomalies such as excess sealant. LLNL has a Cooperative Research and Development Agreement with Bales Scientific Incorporated to commercialize DBIR-CT technology.

Contact:

Nancy Del Grande (510) 422-1010 (delgrande1 @IInl.gov). 


\section{DISCLAIMER}

Portions of this document may be illegible in electronic image products. Images are produced from the best available original document. 